\title{
LA MELOTERAPIA EN EL PENSAMIENTO Y LA OBRA DE ISIDORO DE SEVILLA
}

\section{MUSIC THERAPY IN THE THOUGHT AND WORK OF ISIDORE OF SEVILLE}

\author{
José María Diago Jiménez \\ jdiago@ucm.es \\ ORCID ID: https://orcid.org/0000-0002-2802-582X
}

\begin{abstract}
Resumen
Isidoro de Sevilla (ca. 565-633), Padre y Doctor de la Iglesia, es considerado uno de los más grandes enciclopedistas de la Antigüedad tardía y la Alta Edad Media. Entre los muchos temas que trató se encuentra la música y, dentro de esta, el poder medicinal o sanador de la misma, temática que gozó de una gran tradición literaria en la Antigüedad clásica debido, en gran parte, a la difusión de sus profundas raíces filosófico-musicales, fundamentalmente de índole pitagórica y platónica. En este artículo se localizan y analizan por primera vez todas las reflexiones isidorianas sobre este tema distribuidas por varias obras del obispo hispalense. Para ello se partirá de la tradición clásica y patrística de la que proceden, teniendo en cuenta también el resto del pensamiento musical isidoriano.
\end{abstract}

\section{Palabras clave}

Isidoro de Sevilla, música, ethos musical, medicina, musicoterapia, meloterapia.

\section{INTRODUCCIÓN}

Isidoro de Sevilla (ca. 565-633) trató diferentes ámbitos de la música en muchos lugares de su obra, dedicando a esta disciplina algunos interesantísimos capítulos, entre los que sobresalen con mucha diferencia los ya famosos del Libro III de las Etimologías y de Sobre los oficios eclesiásticos. ${ }^{1}$ Los muy

\footnotetext{
${ }^{1}$ Para la edición crítica de referencia del libro III de las Etimologías, véase Giovanni Gasparotto y Jean-Yves Guillaumin, Isidorus Hispalensis. Etymologiae III, texto establecido por Gasparotto, traducido y comentado por Guillaumin (París: Les Belles Lettres, Auteurs latins du Moyen Âge, 2009; en adelante ALMA). Para el Libro IV de las Etimologías, también referenciado en este artículo y no editado en ALMA, se
}

\begin{abstract}
Isidore of Seville (ca. 565-633), Father and Doctor of the Church, is considered one of the greatest encyclopaedists of Late Antiquity and the High Middle Ages. Among the many topics he dealt with was music and, within this, its medical or healing power, a topic that enjoyed a great literary tradition in Classical Antiquity due, in large part, to the diffusion of its deep philosophical-musical roots, fundamentally of a Pythagorean and Platonic nature. This article locates and analyzes for the first time all the Isidorian reflections on this topic distributed throughout several works of the bishop of Seville. In order to do this, the classical and patristic tradition from which they originate will be used, taking also into account the rest of the Isidorian musical thought.
\end{abstract}

\section{Key words} therapy.

Isidore of Seville, music, ethos in music, medicine, music

utilizará la edición clásica de W. M. Lindsay, Isidori Hispalensis Episcopi Etymologiarum sive Originum libri XX, recognovit brevique adnotatione critica instruxit, 2 vols. (Oxford: Oxford Classical Texts, 1971). Para la traducción castellana de estos libros, véase Isidoro de Sevilla. Etimologías. Edición bilingüe, texto latino, versión española y notas por José Oroz Reta y Manuel A. Marcos Casquero (Madrid: Biblioteca de Autores Cristianos, 2004; en adelante Etym.BAC). No obstante, antes que cualquier traducción, recomiendo leer preferentemente el texto latino. Del mismo modo, es preciso indicar que la edición de la colección ALMA del Libro III, la utilizada en este artículo, no considera el capítulo 14 de la edición clásica de Lindsay, añadiéndolo al final en forma de apéndice. Por tanto, la numeración de los capítulos de esta edición varía en relación a la de Lindsay, siendo un número menos desde ese mismo capítulo 14 en la edición de ALMA que en la edición clásica de Lindsay. 
esporádicos estudios musicales isidorianos publicados hasta la fecha se han centrado en comentar, en su mayoría de manera superficial, los aspectos más destacables de estos capítulos, ignorando el resto de las reflexiones musicales del obispo hispalense. ${ }^{2}$ Lo mismo puede decirse sobre los textos de medicina, disciplina a la que Isidoro dedicó íntegramente el Libro IV de las Etimologías, lo que también ha provocado que este libro se haya convertido en el objeto exclusivo de los todavía más escasos estudios médicos isidorianos. ${ }^{3}$

De los puntos en común de estos dos mundos, el musical y el médico, aunque con especial relevancia del primero en relación al segundo, surge un tema fundamental al que no han prestado atención alguna los estudios musicales, filológicos y médicos isidorianos publicados hasta la fecha: el poder sanador de la música, que es tratado por el obispo hispalense en diferentes lugares de su obra. Por otra parte, es fundamental aclarar que con la expresión "poder sanador de la música" me estoy refiriendo exclusivamente a la meloterapia; es decir, únicamente al poder sanador del mélos, dejando a un lado el poder sanador de la palabra. ${ }^{4}$

Por otra parte, es preciso indicar que en este trabajo se siguen fielmente las distintas ediciones críticas utilizadas, aunque eso conlleve que en casos como, por ejemplo, el uso de $v / u$ se usen en alguna ocasión grafías distintas para una misma palabra.

${ }^{2}$ Entre estos estudios destacan las aportaciones de Francisco José León Tello, "La teoría musical en las obras de Isidoro de Sevilla", Música. Revista Trimestral de los Conservatorios Españoles, 1 (1952), pp. 11-28, la mejor investigación de este autor sobre el tema; y, sobre todo, el trabajo de Jacques Fontaine, Isidore de Seville et la culture classique dans L'espagne wisigothique (París: Études Augustiniennes, 1983, segunda edición revisada y corregida, en adelante $I S C C$ ), donde se dedica a la música las páginas 413-440, que contienen el análisis más completo y profundo de cuantos se han realizado hasta el día de hoy y, además, presentan un interesante estado de la cuestión de los trabajos publicados hasta ese momento. Tras la publicación de ISCC, tan solo algunos trabajos han aportado verdaderas novedades a lo ya dicho por Fontaine. Entre estos destaco los siguientes: Joseph R. Jones, "Isidore and the Theater", Comparative Drama, 16/1 (1982), pp. 26-48; L. M. G. Cerqueira, "A música especulativa nas Etymologiae de Isidoro de Sevilha”, Modus 6 (2006), pp. 143-179, que incluye otras publicaciones anteriores de este autor; y Michel Huglo, "La tradición de la Musica Isidori en la Península Ibérica", en Susana Zapke, Hispania Vetus. Manuscritos litúrgico-musicales de los orígnes visigóticos a la transición francorromana (siglos IX-XII) (Bilbao: Fundación BBVA, 2007), pp. 61-93, el estudio más reciente de este autor que, en esencia, también se apoya en otras investigaciones propias anteriores.

3 Véase Arsenio Ferraces Rodríguez, ed., Isidorus medicus. Isidoro de Sevilla y los textos de medicina (A Coruña: Universidade da Coruña, 2005).

${ }^{4}$ Utilizo el término meloterapia en lugar del castellano musicoterapia porque es el más correcto teniendo en cuenta la materia a la que nos referimos, ya que estamos hablando de un aspecto característico y originario de la música y la cultura griega antigua. El término griego $\mu$ ć̀os (mélos) tiene un significado muy amplio. No obstante, siempre tiene un componente común en todas sus acepciones y usos: hace referencia a la altura tonal de los sonidos. Los que varían son los matices que podemos encontrar en los distintos usos del término. Por tanto, de acuerdo con las pala-
Por tanto, el objetivo de este artículo es localizar, clasificar, contextualizar y analizar por primera vez todas las reflexiones musicales isidorianas que tratan el poder curativo de la música y que se encuentran desperdigadas por varios pasajes de la obra del doctor hispalense, relacionándolas con los fundamentos filosófico-musicales clásicos y patrísticos en las que se basan, y con el resto del pensamiento musical isidoriano. Este estudio consta de tres apartados dedicados a: 1) contexto filosófico-musical de las reflexiones sobre el poder medicinal de la música en la obra de Isidoro de Sevilla; 2) localización, clasificación y análisis de las referencias isidorianas sobre meloterapia, la sección más extensa que incluye tres ejemplos de curaciones concretas a través de la música; y 3) la meloterapia en la Hispania visigoda. Por último, y a modo de conclusión, se indicará el lugar que ocupa la meloterapia en el pensamiento musical isidoriano partiendo de las principales ideas expuestas.

\section{CONTEXTO FILOSÓFICO-MUSICAL DE LAS REFLEXIONES SOBRE EL PODER MEDICINAL DE LA MÚSICA EN LA OBRA DE ISIDORO DE SEVILLA}

La justificación filosófico-musical de todas las reflexiones sobre el poder medicinal de la música que se pueden leer en la obra de Isidoro tiene su origen en los planteamientos pitagóricos y platónicos que relacionan - partiendo del concepto pitagórico del número- el universo, la música y el hombre. ${ }^{5} \mathrm{La}$

bras de Isidoro y con la propia tradición musical grecolatina anterior, al hablar del poder sanador del mélos me estoy refiriendo al poder sanador de la música, de los sonidos musicales, de la pura melodía (con el ritmo), distinguiéndolo del poder sanador de la palabra, práctica también frecuente en la Antigüedad, aunque, en muchas ocasiones el poder curativo de la palabra pueda ir asociado al de la música debido a la propia concepción de la música griega. Para el empleo de la palabra con fines terapéuticos en la Antigüedad, véase Luis Gil Fernández, Therapeia. La medicina popular en el mundo clásico (Madrid: Triacastela, 2004), pp. 217-244. Para una visión general y completa de la meloterapia en la Antigüedad, véanse Gil Fernández, Therapeia, especialmente pp. 283-326; Andrew Barker, Psicomusicologia nella Grecia Antica, a cura di Angelo Meriani (Nápoles: Guida, 2005), pp. 75-95 y 131-141; y Joël Figari, "Musique et médicine dans la philosophie présocratique", en Musique \& Antiquité. Actes du colloque d'Amiens, ed. Odile Mortier-Waldschmidt (París: Les Belles Lettres, 2006), pp. 121-145. Por otra parte, es importante destacar que el poder sanador de la palabra en algunas de sus variantes como el exorcismo debió ser una práctica frecuente en épocas posteriores como la Hispania visigoda de Isidoro. Para el exorcismo, véase Gil Fernández, Therapeia, pp. 326-333; sin embargo, hay que dejar claro que el exorcismo se encuentra dentro del uso terapéutico de la palabra, desligándola del uso de la melodía.

5 El pensamiento musical platónico, aunque genuino, complejo y profundo, tiene una clara inspiración pitagórica, por lo que, desde el comienzo de la difusión de la doctrina platónica aparece fuertemente unido con el pensamiento musical pitagórico y así lo asimilaron muchos autores posteriores. La filosofía de Pitágoras de Samos (s. VI-V a. C.) se basa en el número, principio fundamental y ordenador del cosmos — término 
denominada harmonia de las esferas, idea de origen pagano, fue asimilada por los Padres de la Iglesia, entre los que destaca por encima del resto Agustín de Hipona, quien trató de argumentar la existencia de unos números musicales perfectos de carácter metafísico que relacionan esta harmonía del universo con el alma del hombre y Dios. ${ }^{6}$ El obispo de Hipona es, con diferencia, el Padre de la Iglesia que más influencia tiene sobre Isidoro en estos temas, constituyendo una vía directa por la que llegan parte de estos conocimientos al doctor hispalense. ${ }^{7}$

este último que, precisamente, significa orden - y principio, por tanto, de todas las cosas que lo componen. Filolao de Crotona, filósofo pitagórico del siglo V a. C. y discípulo casi directo de Pitágoras, afirma que todo lo conocido tiene un número que está en la base de todas las cosas, en su esencia, en las cosas divinas y humanas y, por supuesto, en la música; véase Hermann Diels y Walther Kranz, Die Fragmente der Vorsokratiker. Griechisch und Deutsch, 3. vols. (Dublin y Zurich, 1975), Frs. 1408,$4 ; 412$, 4. Este es un ejemplo, capital por su antigüedad, de la especial predilección que la escuela pitagórica siempre mostró por el estudio metafísico del número y por las disciplinas matemáticas. En base a ese principio, los pitagóricos tratan de explicar la música juzgándola siempre desde el punto de vista de la razón, desde el punto de vista filosófico y teórico-conceptual, por encima del de la percepción, del punto de vista práctico - hecho que, debido a su influencia, tendrá una repercusión fundamental para la historia de la música. Su doctrina musical es compleja, pero se puede simplificar en dos ideas básicas. En primer lugar, los pitagóricos consideran que la música está constituida por una serie de razones o proporciones ( $\lambda$ ó $\gamma \mathrm{o}$, , lógos) que no son sino el reflejo de ese principio fundamental y ordenador del cosmos: el número. En segundo lugar, defienden una clara relación e influencia de la música en el alma del hombre, la naturaleza y el universo (regidos todos por ese mismo principio, esos mismos números, razones o proporciones que también se hallan en la música). Para una visión general de la doctrina pitagórica, véanse Walter Burkert, Lore and Science in Ancient Pythagoreanism (Cambridge, MA: Harvard University Press, 1972); y Joël Figari, La philosophie pythagoricienne de la musique (París: Université de Paris IV Sorbonne, 2002). Para una visión general del pensamiento musical platónico, véase Evanghélos Moutsopoulos, La musique dans l'oeuvre de Platon (Paris: Presses Universitaires de France, 1989).

${ }^{6}$ Para reflexiones de carácter general sobre la idea de harmonía de la música griega y, por extensión, romana - en cualquiera de las múltiples acepciones del término, así como en otras posibles - se escribirá harmonía con $h$ con el fin de de diferenciar el concepto griego de harmonía, del concepto moderno de armonía. Ha de notarse que es la grafía utilizada en la mayoría de los textos científicos castellanos más actuales que hablan sobre este término griego. Por otra parte, he de indicar que se respetará la ortografía de las ediciones críticas y traducciones al castellano utilizadas, aun cuando escriban el término $\sin h$.

${ }^{7}$ La influencia de Agustín (ca. 354-430) es determinante en el pensamiento musical occidental y en el pensamiento musical isidoriano, influencia que se observa, además, en otras muchas facetas del obispo hispalense a lo largo de toda su obra.

Las reflexiones agustinianas más profundas sobre este tema se encuentran en su De musica (y, dentro de esta obra, en el Libro VI), donde analiza en profundidad los fundamentos matemáticos y filosóficos de la harmonía de las esferas, del canto del universo. En su Libro I (el único libro que tiene un carácter filosófico y especulativo junto con el Libro VI) analiza el carácter de los números y de sus proporciones desde una pers-

\subsection{Música, número y universo en la obra de Isidoro de Sevilla. La harmonía de las esferas ${ }^{8}$}

Isidoro recoge la idea y tradición literaria de la harmonía o música de las esferas y expone su particular concepción de la

pectiva pitagórica; números y proporciones que le servirán para explicar los distintos pies, versos y metros a lo largo de todo el tratado (Libros IIV). Basándose, solo en parte, en esta fundamentación pitagórica expuesta en el Libro I, dedica el Libro VI, caracterizado por un ferviente y apasionado cristianismo que contrasta con los otros cinco libros anteriores, a explicar su concepción de la harmonía de las esferas, reflexionando (desde una perspectiva enormemente neopitagórica) sobre la relación de la música con el alma del hombre y la esfera de lo divino (partiendo de los diferentes números que la constituyen, de los más sensibles a los eternos e inmutables, ya que todos constituyen la harmonía del universo), así como sobre la capacidad de la música para permitir y ayudar al alma del hombre a abandonar el mundo corpóreo y sensible para ascender hasta el mundo incorpóreo y metafísico; es decir, para ascender hasta Dios, que es el creador, en palabras de Agustín, del "carmen uniuersitatis". Para más información pueden verse Guillermo León Correa Pavón, Numerus-proportio en el De Musica de san Agustin (Libros I y VI). La tradición pitagórico-platónica, tesis doctoral (Salamanca: Universidad de Salamanca, 2009), con abundante bibliografía fundamentalmente musical y matemática en pp. 204-216; Henri Irenée Marrou, Traité de la musique selon l'esprit de Saint Augustin (Neuchatel: La Baconnière, Cahiers du Rhône, 1942); y Paloma Otaola, El De musica de san Agustín y la tradición pitagórico-platónica (Valladolid: Estudio Agustiniano, 2005), con selección bibliográfica de carácter más filosófico y general que también incluye bibliografía matemática en pp. 150-156.

${ }^{8}$ La idea de la harmonía o música de las esferas estuvo presente en el concepto musical griego hasta la época de Platón, pero fue este gran filósofo quien le otorgó una cierta entidad metafísica al plasmarla por escrito en un texto que la fundamentaba: el famoso pasaje del Timeo (29d-47e) en el que narra la creación del alma del universo y del hombre mediante proporciones o razones numéricas, las mismas que otorgan el carácter harmónico a los sonidos y a los ritmos musicales. La harmonía de las esferas establece una serie de conexiones entre las proporciones musicales y las proporciones del universo, de todo lo que nos rodea y del alma del hombre - partiendo del principio pitagórico del número-, por lo que todo el universo se halla en perfecta harmonía (todo es cos$m o s)$, y esa harmonía se encuentra también en todas las esferas celestes y planetarias, afectando, según las fuentes, a su composición, razón de ser, situación, movimiento y sonido. Los tratadistas posteriores en muchas ocasiones se limitaban a acudir al texto platónico en busca de autoridad y otras veces realizaban verdaderos comentarios. La relación entre la música y el universo fue tratada a lo largo de toda la Edad Antigua por autores paganos y cristianos de la talla de Teón de Esmirna, Nicómaco, Ptolomeo, Clemente de Alejandría, Porfirio, Jámblico de Calcis, Atanasio de Alejandría, Arístides Quintiliano o Proclo en el ámbito griego (por señalar, probablemente, a algunos de los más grandes autores griegos en materia de música junto a Aristóxeno), o Cicerón, Plinio el Viejo, Quintiliano, Censorino, Agustín, Favonio Eulogio, Macrobio, Marciano Capela, Boecio y Casiodoro en el ámbito latino. Al respecto pueden verse, entre otros, Gabriela Roxana Carone, Plato's Cosmology and its ethical dimensions (Cambridge: Cambridge University Press, 2005); Francis M. Cornford, Plato's Cosmology (Londres: Hackett Publishing Company, 1971); Joscelyn Gowdin, Armonía de las esferas (Gerona: 
misma mediante una doble vía: como excelente enciclopedista tardoantiguo (Etym.3.16.1 y Etym.3.22.2) ${ }^{9}$ y como Padre de la Iglesia (Quaest.in I Reg.9.3-4). ${ }^{10}$ Por una parte, se basa directa o indirectamente en otros textos de carácter técnico de la tradición grecolatina pagana de origen pitagórico y platónico, entre los que destacan los de Quintiliano (1.10.11-13), ${ }^{11}$ Casiodoro (Inst. 2.5.8) ${ }^{12}$

Atalanta, 2009); K. v. Jan, "Die Harmonie der Shpären”, Philologus, 52 (1894), pp. 13-37; Jesús Luque Moreno, "Letras, notas y estrellas. $1^{\text {a }}$ Parte", MHNH. Revista internacional de investigación sobre magia y astrología antiguas, 11 (2011), pp. 506-517; "2 2 Parte”, 12 (2012), 199236; y Moutsopoulos, La musique dans l'oeuvre de Platon. Véanse también Andrew Barker, Greek Musical Writings, 2 vols. (Cambridge: Cambridge University Press, 1984) y M. L. West, Ancient Greek Music (Oxford: Clarendon Press, 1992).

${ }^{9}$ Los autores y obras antiguos y altomedievales se citarán de manera abreviada teniendo en cuenta el listado de abreviaturas de la versión en línea del Diccionario Griego-Español, CSIC (DGE), y, para aquellos autores y obras que no aparecen en el $D G E$, el listado de abreviaturas del Thesaurus Linguae Latinae (TLL). No obstante, se ha preferido homogeneizar todas las referencias mediante el sistema autor.título.libro. capítulo.parágrafo. Del mismo modo, he de indicar que existen algunas excepciones que no siguen estas normas, entre las que destacan Casiodoro, con quien se ha simplificado la abreviatura de Inst. Div. a Inst, Galeno, con cuyas obras se sigue la abreviación y numeración indicadas en el $D G E$, y Plutarco, con cuyas obras se ha utilizado el listado de abreviaturas del Oxford Classical Dictionary (Oxford: Oxford University Press, 2012) por considerarlo mucho más preciso y fácil de comprobar en un solo golpe de vista que el del $D G E$.

${ }^{10}$ Se trata de los parágrafos 3 y 4 del capítulo 9 del comentario al Primer Libro de los Reyes de las Cuestiones sobre el Antiguo Testamento. Hay que indicar que esta obra también es conocida como Mysticorum expositiones sacramentorum y que no existen ediciones críticas modernas del texto, por lo que para su lectura hay que recurrir a la $\mathrm{Pa}$ trología Latina (se encuentra en PL 83, col. 207-424). Por tanto, cuando se expongan las referencias musicales de esta obra, aportaré mis propias traducciones.

${ }^{11}$ Quintiliano (s. I d. C.), personaje de origen hispano y enormemente influyente en el pensamiento musical de Isidoro de Sevilla, fue uno de los rétores y pedagogos más famosos e influyentes de toda la historia de Roma gracias, en gran medida, a su magna obra Institutio oratoria, en la que a lo largo de doce libros analiza los conocimientos que ha de alcanzar un buen orador, tratando prácticamente todos los aspectos fundamentales del arte retórico conocidos hasta la fecha. En el Libro I de su tratado expone los distintos conocimientos pertenecientes a otras disciplinas liberales que, a su juicio, ha de dominar un buen orador, entre los que se encuentran, lógicamente, los conocimientos musicales (en 1.10.9-33). Es difícil precisar si Isidoro leyó a Quintiliano directamente o lo hizo a través de fuentes secundarias

${ }^{12}$ Casiodoro (ca. 490-580) es considerado uno de los grandes enciclopedistas del periodo de transición entre la Antigüedad Tardía y la Alta Edad Media junto a Boecio y al propio Isidoro. Sus textos musicales más importantes son los transmitidos en sus Instituciones, obra fundamental para Isidoro, pues se basa, con gran dependencia, en ella para construir los tres primeros libros de las Etimologías. Para la edición crítica de las Instituciones, véase R. A. B. Mynors, Cassiodori Senatoris Institutiones (Oxford: Clarendon Press, 1937). Existe una traducción española de la parte dedicada a las disciplinas liberales, que es la que y, quizás, Capela. ${ }^{13}$ Por otra parte, utiliza fuentes patrísticas anteriores en las que se observa la asimilación de estos conceptos dentro del pensamiento cristiano: los textos de Augustín (Ciu.17.14) y Nicetas de Remesiana (Psalm.1). ${ }^{14}$ Estas últimas son las reflexiones verdaderamente importantes — reflexiones desconocidas por la crítica y no tenidas en cuenta en ningún estudio musical isidoriano anterior - para comprobar el alcance de esta idea en el pensamiento musical del hispalense, ya que gracias a ellas se puede observar cómo Isidoro no es un mero transmisor de estos conocimientos de origen pagano recogidos en la literatura musical de carácter técnico, sino que son la prueba de que los ha asimilado plenamente dentro de un pensamiento puramente cristiano. En la harmonía de las esferas isidoriana el número pitagórico deja paso al número divino, es decir, al poder, la grandeza y la perfección de la obra de Dios.

Para Isidoro, quien diferencia claramente los planos metafísico - y, dentro de este, uno más propiamente ontológicoy acústico de esta idea, es Dios el autor de la harmonía de las esferas. Esa harmonia sonorum está en la base de todo lo creado, incluido el hombre, y también sustenta, relaciona y ordena todo el universo en suma perfección, en suma harmonía, desde las más altas esferas planetarias, que a su vez producen su sonido perfecto y harmonizado, hasta el propio hombre, su alma y su cuerpo (el microcosmos), y, en definitiva, el resto de la creación, puesto que Isidoro también defiende la relación y la influencia de la música en el comportamiento de otros seres vivos. Para el doctor hispalense, esa harmonía de las esferas, esa har-

interesa en este trabajo, que muestra excesiva dependencia de la traducción de Etym.BAC. Dicha traducción se puede ver en Casiodoro. Institutiones saecularium litterarum. Las siete artes liberales, traducción por Mari Cruz Ramos Torres (Valdemorillo: La hoja del monte, 2009). En este artículo tan solo se indicarán las ediciones críticas y traducciones al castellano de los pasajes citados literalmente.

${ }^{13}$ Autor africano que vivió probablemente a finales del siglo IV y en la primera mitad del siglo V. Su fama se debe a Las bodas de Mercurio y Filología, compuesta entre el año 410 y el 439 , que constituye un relato alegórico cuyo objetivo es mostrar el verdadero camino para pasar del mundo corpóreo, mortal y sensible, hasta alcanzar el mundo incorpóreo, inmortal y racional. Este camino solo puede hacerse a través de la sabiduría, del conocimiento, representado por las siete artes liberales. La obra está compuesta por nueve libros. Los dos primeros libros se dedican a presentar este marco alegórico de la obra, mientras que cada uno de los siete restantes está dedicado a cada una de las siete disciplinas liberales en este orden: Gramática, Dialéctica, Retórica, Geometría, Aritmética, Astronomía y Música. Una gran edición del texto se puede leer en Iacobus Willis, Martianus Capella (Leipzig: Teubner, 1983). No existen traducciones completas al castellano de esta obra.

${ }^{14}$ Nicetas de Remesiana fue un escritor latino cristiano que vivió en el siglo IV, gran evangelizador de la Dacia y obispo de Remesiana. Desde el punto de vista musical hay que destacar su papel a la hora de promover el uso litúrgico de la música, así como su papel como compositor, pues se le considera autor de varios himnos. Varios fragmentos de la obra citada en el cuerpo del texto, De psalmodiae bono, en la que trata la música, son copiados de manera casi literal por Isidoro en varios pasajes de su obra. 
monia sonorum, es un signo máximo del poder y la grandeza de Dios, así como de la perfección de toda su obra.

Por tanto, aunque la concepción de la harmonía de las esferas isidoriana sea puramente cristiana, el doctor hispalense expone reflexiones de dos tipos: unas de origen pagano inspiradas fundamentalmente en fuentes paganas y otras puramente cristianas inspiradas en fuentes cristianas, siendo estas últimas - desconocidas para la crítica - las que otorgan el verdadero significado a estas teorías dentro del pensamiento musical isidoriano. Estas apreciaciones son fundamentales, pues, tal y como se podrá comprobar en los apartados siguientes, el obispo hispalense también expondrá dos tipos de reflexiones sobre el poder medicinal de la música: reflexiones que representan lo más genuino de la tradición musical pagana grecolatina - fundamentadas en otras anteriores de origen pagano- y reflexiones puramente cristianas que representan la esencia de la tradición musical patrística - fundamentadas en otras patrísticas anteriores - , siendo estas últimas las que otorgan el verdadero significado a la concepción isidoriana sobre el poder medicinal de la música.

\subsection{Fundamentos filosófico-musicales de la meloterapia isidoriana}

De las diferentes y complejas relaciones de estas concepciones del universo, la pagana y la cristiana (con frecuentes variantes particulares según cada autor), derivan todos los aspectos matemáticos relacionados con la música, así como todos los aspectos relacionados con el ethos musical, es decir, los aspectos relacionados con la influencia que la música puede ejercer sobre el espíritu del hombre (y, por extensión, sobre su propio cuerpo y el resto de la naturaleza), incluyendo algunas de sus variantes más famosas como las utilizaciones educativa y médica de la música. ${ }^{15}$ Todos estos aspectos gozaron de una gran tradición en la literatura musical grecolatina y son tratados por Isidoro en un número considerable de reflexiones distribuidas por toda su obra. ${ }^{16}$

Es muy probable que la meloterapia tuviese un origen popular y ancestral, puesto que, si hacemos caso a las fuentes, podemos observar cómo el pueblo griego creía en estas utilidades terapéuticas de la música desde sus orígenes más remotos. ${ }^{17}$

15 Para el tratamiento ético de la música griega antigua de manera general, véanse la clásica obra de Hermann Abert, Die Lehre von Ethos in der grieschischen Musik (Leipzig: Breitkopf \& Härtel, 1899); Warren D. Anderson, Ethos and Education in Greek Music. The evidence of poetry and philosophy, (Cambridge, MA: Harvard University Press, 1966); y el excelente trabajo ya citado de Barker, Psicomusicologia nella Grecia Antica.

${ }^{16}$ Es preciso destacar el elevado número de estas interesantes reflexiones. Del mismo modo, también hay que destacar que a día de hoy no solo siguen sin ser estudiadas, sino que en su mayoría son unas grandes desconocidas para la crítica.

17 Ya Homero da muestras de ello en su obra cuando, en el Canto IX (185-195) de la Ilíada, el alma de Aquiles sufre una curación milagrosa gracias a la música (pasaje también referido para justificar estos orígenes de la meloterapia por Plutarco -Mus.40- y Sexto Empírico -M.6.10-); o,
Sin embargo, estos planteamientos no hay que entenderlos exclusivamente como pintorescas acciones producidas por creencias populares. Tal y como se ha expuesto anteriormente en relación a la harmonía de las esferas, y tal y como es de esperar teniendo en cuenta la idiosincrasia especulativa del pueblo griego, la utilización médica de la música también fue sustentada filosóficamente a lo largo de toda la Edad Antigua. Luis Gil define con precisión lo acertado de los planteamientos helenos:

Los griegos descubrieron todos los efectos psicológicos y psicosomáticos de la música y les dieron una explicación que, con las lógicas variantes del lenguaje científico, viene a ser en el fondo idéntica o muy similar a la de que desde el Renacimiento a nuestros días se les ha dado. ${ }^{18}$

Los primeros en fundamentar la meloterapia, como ocurre también con muchos otros campos relacionados con la música, fueron los pitagóricos. Ya se ha indicado más arriba que todo parte del concepto filosófico y matemático de número como principio ordenador del cosmos, es decir, número en su dimensión metafísica y número en su dimensión matemática. También se ha indicado que todo el universo está constituido por ese principio del número y que todo el universo es harmonía, ya que la harmonía también está constituida por números y proporciones perfectos. ${ }^{19}$ Para los pitagóricos, las enfermedades son producidas por desajustes de esa harmonía universal, desajustes que pueden ser provocados por múltiples causas. Del mismo modo, la música está constituida por número y la música es harmonía. Por tanto, ese pequeño desajuste de la harmonía universal que produce la enfermedad puede ser ajustado mediante la utilización de la música correcta, de la harmonía correcta, o, dicho de otro modo, del número y la proporción correcta. Los Padres de la Iglesia, igual que asumieron los fundamentos pitagórico-platónicos de la harmonía de las esferas, también asu-

en el Canto I, los aqueos cantan un peán para erradicar la peste que azota su campamento (Il.1.472-474). Del mismo modo, también resulta ilustrativo el comportamiento de Agamenón (Od.3.260-280), quien dejó a un aedo para que calmara las apetencias sexuales de Clitemnestra a través de la música mientras él luchaba en la Guerra de Troya.

${ }^{18}$ Luis Gil Fernández, Therapeia, p. 317.

${ }^{19}$ Harmonía (o armonía) es un término originario y característico de la música griega antigua (transmitido a épocas posteriores con sus consecuentes variaciones de significado) que puede hacer referencia a varios conceptos; desde aspectos relacionados con la pura melodía como puede ser la disposición de los distintos intervalos que configuran una escala o la disciplina musical que estudia la disposición melódica de los sonidos - a aspectos con connotaciones más filosóficas, como puede ser la famosa harmonía de las esferas o los adjetivos harmónico o harmonizado aplicados a una melodía, a saber, perfecta, o a otro término, incluso, ajeno al campo de la música. No obstante, en todos estos casos, la palabra harmonía y otras de la misma familia léxica contienen dentro de sí una idea de "ensamblaje", "juntura", "encaje" "unión”, "ajuste" o, incluso, "proporción" o "ley" que en ningún momento pierden, dando a entender, además, una idea de justedad o perfección en esa unión o ensamblaje. 
mieron, aunque planteándolos desde otro punto de vista y justificándolos de otra manera, todos los aspectos derivados de la teoría ética de la música, entre los que se encuentran estos planteamientos sobre el uso terapéutico de la misma. Sin embargo, tal y como veremos, para los escritores cristianos vuelve a ser Dios y la perfección de su obra la que está detrás de esta posible influencia de la música sobre el hombre y la naturaleza, pues para los Padres de la Iglesia, y parafraseando a Agustín, Dios es el creador del "carmen uniuersitatis".

\section{REFERENCIAS MUSICALES ISIDORIANAS SOBRE LA MELOTERAPIA. LOCALIZACIÓN, CLASIFICACIÓN Y ANÁLISIS}

Una vez contextualizada la fundamentación filosófico-musical de las reflexiones isidorianas que tratan la meloterapia , así como la doble vía por la que llegan a Isidoro a través de la literatura tardoantigua, es el momento de pasar a analizar las propias reflexiones isidorianas sobre la meloterapia, partiendo, una vez más, de los fundamentos clásicos y patrísticos de las mismas e incidiendo, por tanto, en las fuentes y las tradiciones musicológicas por las que llegan estos conocimientos a Isidoro.

El doctor hispalense dedica al poder sanador de la música una serie de interesantes reflexiones repartidas por diversos lugares de su obra que demuestran unas estrechísimas y densas conexiones con la tradición literaria anterior. Dichas reflexiones se encuentran en tres pasajes de sus Etimologías (Etym.3.16.3, Etym.4.4.1 y Etym.4.13.3) y en dos extensos pasajes de sus Cuestiones sobre el Antiguo Testamento, concretamente en los capítulos 9 (parágrafo 4) y 12 (parágrafos 1 y 2) del comentario al Primer Libro de los Reyes (Quaest.in I Reg.9.4, 12.1-2). Estas noticias las podemos dividir en dos tipos según su contenido. En primer lugar, se pueden observar reflexiones de carácter general acerca del poder medicinal de la música (Etym.3.16.3 y Etym.4.13.3). En segundo lugar, también se pueden leer varios ejemplos de curaciones concretas realizadas por famosos personajes a través de la música. Al segundo grupo pertenecen todas las reflexiones restantes y nuevamente una reflexión de Etym.3.16.3 y otras dos de Etym.4.13.3. La primera de estas dos noticias expuestas en Etym.4.13.3 coincide parcialmente (en contenido y forma) con la expuesta en Etym.3.16.3. Estos aspectos son explicados con más detalle a continuación.

\subsection{Reflexiones isidorianas de carácter general. Fundamentos clásicos y patrísticos. Las fuentes isidorianas.}

Desde dentro del planteamiento de origen pitagórico que, como se ha empezado a ver y se verá más adelante, llega a Isidoro a través del neoplatonismo, pagano o cristiano, y el enciclopedismo tardoantiguo - es desde donde hay que entender las ideas generales que expone el doctor hispalense sobre la estrecha relación entre el cuerpo humano y la música; principalmente la expuesta en Etym.3.16.3, ya que es la idea que justifica filosóficamente su posición ante la meloterapia: "Sed et quidquid loquimur uel intrinsecus uenarum pulsibus commouemur per musicos rythmos armoniae uirtutibus probatur esse sociatum". ${ }^{20}$ Ya se expuso más arriba que para Isidoro, como para cualquier cristiano, todo lo creado es obra de Dios: el universo, el alma del hombre, el cuerpo humano y la música; todo forma parte de la harmonía universal. Por tanto, desde el punto de vista metafísico, la utilización médica de la música (de origen y fundamentación paganas) no solo no contradice en esencia al pensamiento cristiano, sino que queda plenamente justificada dentro del mismo.

La segunda de estas referencias (Etym.4.13.3) se ha de entender desde un punto de vista totalmente literal, siendo, sin duda, una consecuencia de la anterior: "Porro Musica incognita illi non erit, nam multa sunt quae in aegris hominibus per hanc disciplinam facta leguntur". ${ }^{21}$ El pasaje Etym.4.13 (recuérdese que el Libro IV está dedicado a la medicina) habla sobre cómo contribuyen las distintas artes liberales a la formación de un buen médico. Por tanto, en este pasaje Isidoro está indicando que el médico no debe ignorar la música por los motivos expuestos. Se trata de una breve introducción a los dos ejemplos concretos de curaciones a través de la música que el obispo hispalense va a exponer a continuación en ese mismo fragmento.

La fuente directa del pasaje de Etym.3.16.3, al igual que de la gran mayoría de las referencias sobre la utilización médica de la música, es Casiodoro, quien escribe en Inst.2.5.2: "quicquid enim loquimur vel intrinsecus venarum pulsibus commovemur, per musicos rithmos armoniae virtutibus probatur esse sociatum. musica quippe est scientia bene modulandi; quod si nos bona conversatione tractamus, tali disciplinae probamur semper esse sociati". ${ }^{22}$ Por tanto, se puede observar una copia prácticamente literal de parte del texto casiodoriano. De hecho, si simplificamos el fragmento de Casiodoro, podemos observar esta coincidencia casi literal en el siguiente cuadro comparativo.

\begin{tabular}{|c|c|}
\hline ISIDORO & CASIODORO \\
\hline $\begin{array}{l}\text { Sed et quidquid loquimur uel } \\
\text { intrinsecus uenarum pulsibus } \\
\text { commouemur per musicos } \\
\text { rythmos armoniae uirtutibus } \\
\text { probatur esse sociatum }\end{array}$ & $\begin{array}{l}\text { quicquid enim loquimur vel } \\
\text { intrinsecus venarum pulsibus } \\
\text { commovemur, per musicos } \\
\text { rithmos armoniae virtutibus } \\
\text { probatur esse sociatum. }\end{array}$ \\
\hline
\end{tabular}

Sin embargo, que Isidoro copie a Casiodoro, autor cristiano, no debe conducirnos a error, ya que el escritor itálico, al

\footnotetext{
20 "E incluso cuanto hablamos, y también las íntimas pulsaciones de nuestras venas, muestran por sus ritmos cadenciosos su vinculación a las virtudes de la armonía”.

21 "E incluso no debe ignorar la música, pues muchas son las enfermedades que, como puede leerse en los libros, han sido tratadas utilizando esta disciplina".

22 "Incluso cuando hablamos, las íntimas pulsaciones de nuestras arterias se asocian por su ritmo cadencioso a las virtudes de la armonía, porque la música es la ciencia del modular bien. Si meditamos esto con buena disposición, nos damos cuenta de que estamos asociados siempre a tal disciplina".
} 
igual que Isidoro, es un consumado enciclopedista que recoge esta afirmación de la más genuina tradición clásica pagana, pues se basa directamente en Censorino (12), ${ }^{23}$ quien relaciona esta información con Herófilo de Calcedonia ${ }^{24}$ de quien afirma lo siguiente: "Herophilus autem, artis eiusdem professor, uenarum pulsus rhythmis musicis ait moueri". ${ }^{25}$ También Marciano Capela (9.926) hace referencia al mismo médico: "Herophilus aegrorum uenas rhythmorum collatione pensabat". Por tanto, hablamos de una reflexión de claro origen y filosofía paganos.

La fuente directa del pasaje de Etym.4.13.3 también es Casiodoro (quien, si hacemos referencia al contenido de su texto, vuelve a fundamentar su afirmación en la tradición clásica pagana), concretamente Inst.2.5.9, donde se puede leer: "multa sunt autem, quae in aegris hominibus per hanc disciplinam leguntur facta miracula". Por tanto, se puede observar una estrechísima relación entre ambos textos, el isidoriano y el casiodoriano, en los que aparecen palabras y expresiones exactamente iguales.

\begin{tabular}{|l|l|}
\hline \multicolumn{1}{|c|}{ ISIDORO } & \multicolumn{1}{c|}{ CASIODORO } \\
\hline $\begin{array}{l}\text { Porro Musica incognita illi } \\
\text { non erit, nam multa sunt } \\
\text { quae in aegris hominibus per } \\
\text { hanc disciplinam facta } \\
\text { leguntur }\end{array}$ & $\begin{array}{l}\text { multa sunt autem, quae in } \\
\text { aegris hominibus per hanc } \\
\text { disciplinam leguntur facta } \\
\text { miracula }\end{array}$ \\
\hline
\end{tabular}

\subsection{Ejemplos de curaciones concretas a través de la música. Fundamentos clásicos y patrísticos. Las fuentes isidorianas.}

Isidoro expone tres ejemplos concretos de curaciones realizadas a través de la música. Dos de ellos, citados solo una vez, se encuentran en el Libro IV de las Etimologías, en Etym.4.4.1

${ }^{23}$ Censorino fue un erudito gramático romano que vivió en el siglo III. Lo único que ha pervivido de él es El libro del cumpleaños, una pequeña obrita dotada de un modesto carácter enciclopédico que trata múltiples saberes de su época de un modo resumido aportando noticias y fuentes de autores anteriores. Entre estos saberes destacan los referidos a las materias del quadriuium, especialmente los relacionados con la música y la astronomía. La edición crítica de esta obra se puede ver en Nicolas Sallmann, Censorini De die natali liber ad Q. Caerellium. Accedit anonymi cuiusdam epitoma disciplinarum (Fragmentum Censorini) (Leipzig: Bibliotheca Scriptorum Graecorum et Romanorum, Teubner, 1983; en adelante BT). Para una traducción castellana, véase Censorino. El libro del cumpleaños, traducción y notas por María Nieves Fidalgo Díaz y prólogo de Carlos García Gual (Madrid: Alba Editorial, 2008).

${ }^{24}$ Herófilo de Calcedonia (s. III d. C.) fue el más famoso médico alejandrino junto con Erasístrato. Estudió, entre otras muchas cosas, la cadencia y la intensidad de las pulsaciones cardiacas, de ahí la afirmación de Censorino.

25 "Herófilo, maestro en este mismo arte de la medicina, dijo que los latidos de las venas se producían con ritmos musicales". y Etym.4.13.3, respectivamente. El otro es expuesto hasta en cuatro ocasiones. Dos de ellas en las Etimologías, Etym.3.16.3 y Etym.4.13.3, y otras dos en sendos parágrafos, 9.4 y 12.1-2, del comentario al Primer Libro de los Reyes en las Cuestiones sobre el Antiguo Testamento. No obstante, hay que destacar las ostensibles diferencias entre los tres ejemplos. El primero es un caso especial, ya que es protagonizado por un dios pagano. El segundo ejemplo corresponde a un médico, un "hombre de ciencia" relacionado con el mundo clásico y pagano. El tercero es protagonizado por un personaje bíblico, alejado de la ciencia clásica y relacionado con la tradición cultural judeocristiana. Por tanto, si exceptuamos el caso del dios pagano, Isidoro, al igual que Casiodoro y otros escritores cristianos anteriores, recoge prácticas de meloterapia de las dos principales tradiciones culturales del Occidente latino altomedieval, la grecolatina y la judeocristiana. Del mismo modo, en Isidoro se dan dos modos distintos de utilización médica de la música. Uno de ellos, el del segundo ejemplo, contextualizado dentro de un marco puramente científico (dentro de los avances lógicos de la ciencia grecolatina), mientras que el otro, representado por los ejemplos primero y tercero, se encuadra dentro de un ámbito más cercano a lo divino o lo milagroso. Entre estos dos últimos ejemplos destaca por su importancia el tercero.

\section{2a. Apolo}

En primer lugar, he de señalar una breve noticia que no constituye un ejemplo de curación concreta, pero que constituye el primer ejemplo, cronológicamente hablando, que se puede rastrear en toda la obra de Isidoro que habla sobre una escuela médica que utiliza la palabra y la música para curar. En dicha noticia, situada en Etym.4.4.1, se observa una interesante relación entre Apolo, la música y la medicina, donde se puede leer: "Prima Methodica inventa est ab Apolline, quae remedia sectatur et carmina", noticia que es traducida en Etym.BAC (p. 475) como: "La primera de todas, la metódica, ideada por Apolo, iba acompañada de medicamentos y conjuros". Nótese cómo el término carmina es traducido como conjuros, dando a entender que estamos ante un claro caso de incantum. ${ }^{26}$ Sin embargo, yo considero más acertado traducir carmina con los términos cantos o poemas, ya que me parece muy importante destacar los evidentes matices musicales de dicha palabra, pues el término carmen y los usos que Isidoro hace de él tienen fundamentalmente estos significados.$^{27}$ Además, ha de tenerse en cuenta que

${ }^{26}$ Según Gil Fernández, Therapeia, pp. 217-218, el incantum es una variedad mágica del empleo de la palabra con fines terapéuticos. Se trata de un equivalente de la práctica del ensalmo y el exorcismo.

${ }^{27}$ Aunque se trata de una palabra polisémica, Isidoro la utiliza a lo largo de su obra con significados que hacen referencia a distintas realidades musicales, tal y como puede observarse en: Etym.3.14.1, 3.21.9, 6.2.17, 6.2.20, 6.2.21, 6.19.17, 6.19.18, 8.7.3, 8.7.4, 18.45, Eccl. Off.1.3.1, 1.6.2. De hecho, el propio Isidoro expone la siguiente definición del término (Etym.1.39.4): "Carmen vocatur quidquid pedibus con- 
Apolo es el dios de la música y la poesía, entre otros atributos. ${ }^{28}$ Debido a todos estos condicionantes, considero muy importante que esta noticia isidoriana no debe desligarse de sus connotaciones musicales. Es decir, de la curación mágica a través de los sonidos musicales o de la palabra unida a la música; de ahí que considere más adecuada la utilización de los términos canto o poema, en lugar del más genérico y menos musical conjuro. De todas las noticias que se analizan en este subapartado, esta es la menos importante de cara a obtener conclusiones sobre el verdadero lugar que pudieron ocupar las prácticas de meloterapia en el pensamiento musical isidoriano, pues el doctor hispalense se limita a recoger ideas anteriores y comunes dentro de la tradición clásica que subrayan la asociación de Apolo, un dios pagano, con la música (y la poesía) y la medicina. ${ }^{29}$

$\mathrm{Al}$ igual que hace con otras disciplinas anteriores analizadas en sus Etimologías (incluida la música), Isidoro comienza el Libro IV describiendo la ciencia médica, su etimología y sus inventores (capítulos 1-3). Entre estos últimos destaca a Apolo como creador de la misma, sitúa a continuación a Esculapio ${ }^{30} \mathrm{y}$, tras su muerte, señala un largo declive de la ciencia médica que termina con la aparición de la figura de Hipócrates. ${ }^{31}$ Más adelante, en el capítulo 4, el que nos ocupa, el obispo hispalense atribuye a cada uno de estos tres personajes la creación de una gran escuela médica y describe: en primer lugar, la escuela metódica, atribuida a Apolo ("Prima Methodica inventa est ab Apolline, quae remedia sectatur et carmina"); en segundo lugar, la empírica, atribuida a Esculapio; y, en tercer lugar, la lógica, atribuida a Hipócrates. Sin entrar a analizar las diferencias entre estas escuelas, hay que destacar que Isidoro, al contrario de lo que escribe en relación a las otras dos escuelas, no atribuye

tinetur" ("Se da el nombre de carmen a todo lo que está contenido en versos").

${ }^{28}$ Apolo es el dios protector de las artes y de las musas, quienes forman parte de su corte y le rinden culto en el monte Parnaso. Es el dios de la música y la poesía, expresa sus oráculos en verso e inspira por igual a adivinos, músicos y poetas. Su figura y su culto están relacionados directamente con la lira, instrumento al que algunos autores atribuyen su creación, como ocurre con Isidoro (Etym.3.21.2, Chron.74, segunda versión). También es el dios de las profecías y las predicciones, términos que también puede ser expresados con la palabra carmen. Sin embargo, parece evidente que Isidoro no se está refiriendo a este último significado.

${ }^{29}$ Nótese que Isidoro (en Chron.74, segunda versión) une estas dos facetas de Apolo (la médica y la musical) en una misma noticia, describiendo al dios como el creador de la cítara y la medicina. Sin embargo, el texto que ahora nos ocupa va un paso más allá, pues no se limita a relacionar a Apolo con la música y la medicina, sino que también relaciona estas dos disciplinas entre sí.

${ }^{30}$ Esculapio, o Asclepio en el mundo griego, es hijo de Apolo y Coronis y principal protector de la medicina. A su culto se consagraron diversos santuarios que se convirtieron en verdaderos centros médicos. Entre estos santuarios destacó el de Epidauro.

${ }^{31}$ Hipócrates (ca. 460-370 a. C.) es considerado el padre de la medicina como ciencia independiente, el creador de una influyente escuela y el médico más famoso de la Antigüedad junto a Galeno. "método científico" alguno a la escuela metódica (a pesar de su nombre), afirmando en Etym.4.4.2 que: "methodici nec elementorum rationem observant, nec tempora, nec aetates, nec causas, sed solas morborum substantias". ${ }^{32}$ Por tanto, se puede observar una primitiva escuela médica creada por Apolo que curaba a través del uso de ciertos medicamentos, la música y la palabra. Una escuela de origen divino que, si seguimos al propio Isidoro, no necesitaba entrar a analizar ningún síntoma ni ninguna otra variable del enfermo o del entorno para poder tratar cualquier patología, al contrario de lo que ocurría con las otras dos escuelas. De hecho, y también al contrario que las otras dos escuelas médicas, tampoco necesitaba basarse ni siquiera en la experiencia previa. Esta escuela, por tanto, debido a su origen divino apolíneo curaba las enfermedades directamente de una manera mágica, atribuyendo sus fundamentos médicos y musicales a la propia divinidad de su creador. Debido a todo ello, esta noticia isidoriana ocupa un lugar muy secundario si la comparamos con las otras dos que se analizan a continuación. Isidoro, como buen enciclopedista, se limita a recoger esta noticia por puro interés de anticuario. Por tanto, no se deben sacar conclusiones profundas de ella a la hora de analizar el poder medicinal de la música dentro de la globalidad del pensamiento musical isidoriano.

\section{2b. Asclepíades de Bitinia}

El segundo de los ejemplos que expone Isidoro tiene como protagonista a Asclepiades de Bitinia, famoso médico griego que vivió aproximadamente desde el 130-120 a. C. hasta el 40 a. C y desarrolló su carrera en Roma. ${ }^{33}$ Isidoro le atribuye una curación a través de la música en Etym.4.13.3: "Asclepiades

\footnotetext{
32 "Los metódicos no tenían en cuenta ni el examen de los síntomas, ni las circunstancias temporales, ni la edad ni las causas, sino únicamente la existencia misma de las enfermedades".

${ }_{33}$ Asclepíades de Bitinia realizó una especie de adaptación de la teoría atomista de Leucipo y Demócrito para explicar el funcionamiento del cuerpo humano y la aparición de las distintas enfermedades. Partiendo de ello intentó tratar las diferentes patologías - especialmente las enfermedades mentales y otras dolencias como las picaduras de escorpiones y serpientes - a través de la música, intentando devolver así el equilibrio y la armonía que el cuerpo había perdido debido a la influencia de átomos externos. En algunas ocasiones concretó su teoría indicando qué modos o melodías se debían de aplicar a cada dolencia. De su obra tan solo se han conservado algunos fragmentos, hecho que ha condicionado que su pensamiento se haya transmitido a la actualidad de forma fragmentaria, principalmente a través de fuentes secundarias - es citado por unos cuarenta autores antiguos-, entre las que destacan Celio Aureliano, Celso o, en menor medida, Plinio el Viejo. Para el pensamiento de Asclepíades de Bitinia, su obra y su recepción en otros autores posteriores, véanse Robert Montraville Green, Asclepiades. His life and writings (New Haven, CT: Elizabeth Licht, 1955); J. T. Vallance, The lost theory of Asclepiades of Bithynia (Oxford: Clarendon Press, 1990); y, del mismo autor, "The medical system of Asclepiades of Bithynia", en Wolfgang Haase y Hildegard Temporini, Rise and Decline on the Roman World (Berlin: de Gruyter, 1993), pp. 693-727.
} 
quoque medicus phreneticum quondam per symphoniam pristinae sanitati restituit". ${ }^{34}$

Esta utilización médica de la música ha de ser contextualizada dentro de una tradición cultural y literaria. Desde el punto de vista cultural no constituye un hecho aislado, ya que grandes eruditos - muchos de ellos médicos - defendieron o utilizaron estas prácticas a lo largo de toda la Antigüedad. En la tradición literaria estas prácticas quedan reflejadas a lo largo de toda la literatura grecolatina llegándose a convertir en el mundo tardoantiguo en una especie de lugar común de la literatura musical y médica.

Las referencias a la utilización médica de la música por parte de Pitágoras y los pitagóricos son abundantes a lo largo de toda la Antigüedad y fueron, sin duda, la vía de acceso que los enciclopedistas tardoantiguos -y, por tanto, Isidoro- tuvieron para llegar hasta estas historias relacionadas con la meloterapia. Las tres grandes biografías pitagóricas conservadas, las de Diógenes Laercio, ${ }^{35}$ Porfirio $^{36}$ y Jámblico ${ }^{37}$ - cito principalmente a sus biógrafos debido a las abundantísimas referencias que incluyen - nos transmiten interesante información sobre las utilizaciones médicas de la música por parte de los pitagóricos en general y del maestro fundador en particular. Gracias a ellos sabemos que no sólo utilizaban la música como medicina del alma (Iambl.VP.15, 25, Porph.VP.30, Aristid.Quint.2.19) o para combatir los estados de ánimo violentos o depresivos (Iambl. $V P .15)$, sino que también la utilizaban para combatir el apetito (Iambl.VP.25) y distintas enfermedades corporales (Iambl. $V P .25$, Porph.VP.32-33). Incluso el propio Pitágoras antes de irse a dormir interpretaba con la cítara (Iamb.VP.15, 25, Cens.3) o escuchaba determinados cantos con el objetivo de purificarse (Iambl.VP.15, 25). También se le atribuyen famosas curaciones utilizando la música, como la que realizó a un joven de Tauromenio, ebrio y enamorado, a través de un simple cambio de modo (Iambl.VP.25, S.E.M.6.8).

34 "También el médico Asclepíades devolvió por ella [per symphoniam] a su anterior estado de salud a un enfermo atacado de locura".

${ }_{35}$ Diógenes Laercio fue un doxógrafo griego que vivió en la primera mitad del siglo III. Fue autor de las Vidas y opiniones de los filósofos ilustres, obra constituida por diez libros, muy importantes y siempre a tener en cuenta debido al contenido que transmiten sobre algunas de las principales escuelas filosóficas griegas. La biografía de Pitágoras encabeza el Libro VIII.

${ }^{36}$ Porfirio (ca. 232 d. C. - 304 d. C.) fue un importante filósofo y escritor neoplatónico discípulo de Plotino. Entre otros escritos, fue autor de una breve biografía de Pitágoras, que constituía el primero de cuatro libros de una especie de Historia de la filosofía, hoy perdida.

37 Jámblico de Calcis (nacido entre 240 y 250 d. C. y muerto alrededor del 325 d. C.) fue otro filósofo y escritor neoplatónico, probablemente discípulo de Porfirio, de quien se separó para fundar su propia escuela en Siria. Su Vida pitagórica no es propiamente una biografía como tal, sino un conjunto de reglas y recomendaciones para adaptar el cuerpo y el alma a los modos de vida y la filosofía pitagóricas. Sin embargo, esta obra contiene mayor número de datos biográficos de Pitágoras que ninguna de las otras dos biografías pitagóricas conservadas.
Al igual que ocurrió con la harmonía de las esferas y con el ethos musical en general, estas teorías de origen pitagórico sobre el poder curativo de la música fueron acogidas y estudiadas por muchos de los más grandes eruditos de la época clásica, especialmente por los siguientes pitagóricos — que continuaron su tradición propia-, por Damón ${ }^{38}$ y por Platón. ${ }^{39}$ También Aristóteles y la escuela peripatética ${ }^{40}$ con Teofrasto a la cabeza desarrollaron su propia fundamentación de la meloterapia.$^{41} \mathrm{In}$ cluso autores ajenos a estos temas defendieron estas prácticas, tal y como ocurre con Demócrito, quien comenta que existían curaciones a través de la música para algunas enfermedades y para las picaduras de serpiente (Gell.4.13.3-4). ${ }^{42}$ Posteriormente, estos usos medicinales de la música también fueron refleja-

${ }^{38}$ Fue un filósofo y músico ateniense que vivió en el siglo V a.C. Su pensamiento musical, partiendo de principios de carácter pitagórico, se centra en el estudio de los aspectos éticos, educativos y políticos de la música, otorgando a esta disciplina un lugar principal dentro del sistema educativo $-\mathrm{y}$, por extensión, dentro del sistema político de Atenasgracias a la influencia que esta podía ejercer sobre el espíritu del hombre.

${ }^{39}$ Estas reflexiones las podemos encontrar en Platón y Aristóteles; véase Barker, Psicomusicologia nella Grecia Antica, Capitulo IV, "La tradizione medica", pp. 75-95.

${ }^{40}$ Aunque Aristóxeno, debido a su inclinación filosófica, no trata estas ideas en los textos de su autoría que se han conservado, Plutarco (Mus.43.1146F-1147A) indica que el tarentino consideraba que la música era introducida en los banquetes para calmar los efectos del vino.

${ }^{41}$ Teofrasto fue discípulo y colaborador de Aristóteles y, tras la muerte del estagirita, su sucesor en la dirección del Liceo (323/322 a. C.) hasta el final de su vida (288/284 a. C.). Su pensamiento musical tiene influencia aristotélica, aunque también presenta ciertas y pequeñas aperturas a las escuelas pitagórica y platónica; no obstante, sus reflexiones tienen una originalidad propia. Teofrasto incide en los aspectos psicológicos de la música y reconoce su doble naturaleza, especulativa y perceptiva. Intenta establecer unas relaciones de carácter físico - no numérico en el sentido pitagórico o ético en un sentido más platónico o aristotélico - entre el alma y la música basadas en el movimiento, relaciones que son la base, entre otras cosas, de la meloterapia de la que aquí hablamos. Entre otras obras, escribió un tratado sobre la música no conservado que es citado por Porfirio en su Comentario a la Harmónica de Ptolomeo.

${ }^{42}$ Noticia recogida por Aulo Gelio. Demócrito, nacido en torno al 460 a. C. es el fundador de la escuela atomista junto a Leucipo. Para ellos el universo está constituido por unas unidades mínimas y no divisibles, los átomos, que tan solo pueden ser captados a través del intelecto. Los atomistas explicaron el conocimiento partiendo de la teoría de los efluvios; es decir, partiendo de la existencia de flujos de átomos que se desplazan y que, al separase de las cosas, se imprimen en los sentidos. Los átomos semejantes que están fuera de nosotros influyen en los átomos semejantes que hay en nosotros. Por tanto, dentro de este planteamiento es desde donde se deben entender las utilidades curativas de la música de Demócrito, ya que los átomos de la música pueden influir en los átomos de la dolencia que hay en nosotros, así como en los del resto del organismo. 
dos por distintos autores en la época imperial, tal y como ocurre con Quintiliano (1.10.32)..$^{43}$

Sin embargo, fue la literatura tardoantigua latina creada a partir del influjo del neoplatonismo la que se sintió especialmente atraída por estas prácticas musicales con fines terapéuticos. Entre los autores tardoantiguos vinculados a las escuelas de corte pitagórico y platónico que escribieron sobre la relación entre la música y la medicina destacan Censorino (9.11-13), Marciano Capela (9.926-927), Macrobio (Sat.5.19.11), ${ }^{44}$ Boecio (Mus.1.1) ${ }^{45}$ o Casiodoro (Inst.2.5.2, 2.5.8, 2.5.9). En los pasajes señalados aparecen diferentes ejemplos de curaciones médicas realizadas utilizando la música, constituyéndose como la parte visible de una especie de cadena por la que llegan estos conocimientos hasta Isidoro.

Por último, y no menos importante, hay que destacar que la defensa y la utilización de la meloterapia por parte de médicos como Asclepiades es algo que también se puede observar a lo largo de toda la Edad Antigua y se recoge tanto en los textos de música como en los textos de medicina. El propio Galeno ${ }^{46}$ (5.473, Kühn) nos ofrece un testimonio a través del cual se observa cómo Damón, utilizando la música, curó de una intoxica-

\footnotetext{
${ }^{43}$ Las referencias a estos usos sanadores de la música son frecuentes en este periodo. Así, por ejemplo, se puede observar cómo algunas fuentes hablan sobre ciertas prácticas destinadas a erradicar los malos espíritus que afectan a la salud a través de las vibraciones producidas al agitar o golpear objetos de bronce o hierro (Luc.Philops.15); otras fuentes exponen la utilización medicinal de la música para modificar los estados de ánimo violentos o depresivos (S.E.M.6.18-20); y otras comentan su uso para relajar y dormir a los niños alterados o enrabietados por cualquier dolencia o motivo (S.E.M.6.32).

${ }^{44}$ Macrobio fue un erudito romano de los siglos IV y V. De sus tres obras conservadas destacan dos de carácter enciclopédico, los Saturnales y el Comentario al "Sueño de Escipión" de Cicerón. Esta segunda obra continúa en cierta manera la tradición del comentario de la obra ciceroniana que se puede leer en Favonio Eulogio, pero, en este caso, con unas pretensiones, calidad y profundidad mucho mayores. En dicha obra traza una serie de teorías de inspiración neoplatónica que tratan temas relacionados con algunas de las ciencias del quadrivium: la aritmética, la astronomía y la música.

${ }^{45}$ Boecio (ca. 480-524) es una de las últimas grandes personalidades de la cultura clásica en Occidente y el más genuino representante, junto a Casiodoro e Isidoro de Sevilla, del eslabón que une la Antigüedad tardía y la Alta Edad Media como transmisor de los conocimientos de una época a otra. Relacionadas con el quadrivium, término acuñado por él mismo y expuesto en De arithmetica 1.1 , se han conservado dos obras: De institutione arithmetica, adaptación latina del famoso tratado de aritmética de Nicómaco de Gerasa, y De institutione musica, obra capital para la historia del pensamiento musical occidental que se puede dividir en dos grandes bloques: el primero, de clara inspiración pitagórica, constituido por los cuatro primeros libros; el segundo, de inspiración ptolemaica, compuesto por el quinto.

${ }^{46}$ Galeno, que vivió a lo largo del siglo II, fue el médico más importante de su época y, junto con Hipócrates, el médico más famoso de la Antigüedad. Su influencia perduró hasta el Renacimiento.
}

ción etílica a un muchacho que había bebido mucho vino. ${ }^{47}$ Teofrasto, quien, como ya he expuesto, sin ser un médico, también estudia a fondo la meloterapia, llega a afirmar que los dolores de la ciática disminuyen con la música (Gell.4.13.1-2). Celso $(3.10)^{48}$ indica que la música y los ruidos son válidos para tratar los estados anímicos. Del mismo modo deben recordarse los casos expuestos más arriba de Herófilo de Calcedonia (Cens.12 y Mart.Cap.9.926) o el caso isidoriano de Asclepíades.

Por tanto, la referencia a Asclepíades expuesta por Isidoro se encuentra totalmente arropada por la rica tradición anterior científica y médica que es reflejada en la no menos rica tradición literaria que mencionábamos más arriba. La fuente de este fragmento vuelve a ser Casiodoro, a quien Isidoro parece resumir y copiar casi al pie de la letra. Casiodoro escribe en Inst.2.5.9: "Asclepiades quoque, medicus maiorum attestatione doctissimus, freneticum quendam per symphoniam naturae suae reddidisse memoratur". ${ }^{49} \mathrm{Y}$, una vez más, este último autor parece que, quizá, se vuelve a inspirar en Censorino (12.4) o también en Capela (9.926), apareciendo nuevamente la tradición pagana como fundamento de las reflexiones médicas isidorianas.

\begin{tabular}{|l|l|}
\hline \multicolumn{1}{|c|}{ ISIDORO } & \multicolumn{1}{c|}{ CASIODORO } \\
\hline $\begin{array}{l}\text { Asclepiades quoque medicus } \\
\text { phreneticum quondam per } \\
\text { symphoniam pristinae } \\
\text { sanitati restituit }\end{array}$ & $\begin{array}{l}\text { Asclepiades quoque, medicus } \\
\text { maiorum attestatione } \\
\text { doctissimus, freneticum } \\
\text { quendam per symphoniam } \\
\text { naturae suae reddidisse } \\
\text { memoratur }\end{array}$ \\
\hline
\end{tabular}

\section{2c. El rey David}

El tercero de estos ejemplos, de claro origen bíblico (1Re.16.14-23), ${ }^{50}$ narra la curación de Saúl por parte de David..$^{1}$

47 Esta idea se repite fundamentalmente con Pitágoras y también en obras de otros autores como Filodemo, Quintiliano, Sexto Empírico, Jámblico, Capela o Boecio. Nótese que ya hemos indicado algo parecido unas notas más arriba sobre una noticia que nos traslada Plutarco en relación a una reflexión aristoxénica sobre el uso de la música en los banquetes para contrarrestar los efectos del vino.

48 Notable enciclopedista y escritor latino y, probablemente, médico que vivió en la época de Augusto. Su única obra conservada, De medicina, constituida por ochos libros, fue un texto que gozó de gran prestigio desde su aparición, siendo una de las mejores obras que reflejan la ciencia médica alejandrina.

49 “También hay que recordar que Asclepiades, médico doctísimo según el testimonio de los mayores, le había devuelto la salud a cierto loco con la ayuda de una sinfonía de su propia creación".

50 Nótese que en relación a la Biblia utilizada actualmente estamos hablando del Primer Libro de Samuel.

51 El rey David es uno de los personajes más importantes para la tradición judeocristiana, rey de Israel y el músico bíblico por excelencia. Las referencias en el Antiguo Testamento que hablan sobre los conocimientos y habilidades musicales de David se distribuyen principal- 
Este episodio médico-musical es expuesto en diferentes lugares del corpus isidoriano: 1) En dos partes distintas de sus Etimologías, la primera en Etym.3.16.3: "Excitos quoque animos musica sedat, sicut de David legitur, qui a spiritu inmundo Saulem arte modulationis eripuit"; 52 y la segunda en Etym.4.13.3, al hablar de las utilidades de las distintas artes liberales en la medicina: "sicut de David legitur, qui ab spiritu inmundo Saulem arte modulationis eripuit". ${ }^{3}$ 2) En otras dos secciones distintas del comentario al Primer Libro de los Reyes de las Cuestiones sobre el Antiguo Testamento. La primera aparece en el parágrafo 9.4:

Iste adhuc puer in cithara suaviter, into fortiter canens, malignum spiritum, qui operabatur in Saule, compescuit, non quod citharae illius tanta virtus erat, sed quod figura crucis Christi, quae de ligno et extensione nervorum mystice gerebatur, ipsaque passio, quae cantabatur, iam tunc spiritus daemonis opprimebat..$^{54}$

La segunda se reparte en los dos parágrafos del capítulo 12, que lleva por título De David repellente cithara spiritum:

1. Auxit deinde odium Saul adversus David in tantum, ut rex ad medetam sui spiritus David de more psallentem iaculo conaretur configere. Sed quid est, quod dum Saulem spiritus adversus invaderet, apprehensa David cithara, eius vesaniam mitigabat?

2. Per Saulem enim Iudaeorum elatio, per David autem humilitas Christi significatur. Cum ergo Saul ab immundo spiritu arripitur, David canente, eius vesania temperatur, quia

mente por los dos libros de Samuel y el primer Primer Libro de las Crónicas; mención aparte merecen los salmos, pues la Biblia hebrea le atribuye la autoría de setenta y tres. Estas referencias describen a un personaje que dominaba absolutamente todos los ámbitos de la música y no solo los puramente prácticos, ámbitos en los que David destacó sobradamente por encima de sus contemporáneos, ya que aparece caracterizado de manera expresa como excelente cantor, instrumentista, bailarín y compositor. Además, hay que destacar su importante papel dentro de la organización del culto y su música y, quizá, la dirección musical del mismo. Evidentemente, las fuentes bíblicas también lo describen haciendo uso de la meloterapia, pues utiliza la música para curar a Saúl. David es citado por Isidoro musicalmente hablando muchas más veces que cualquier otro personaje, bíblico o mitológico, histórico o legendario. Además, algunas de las noticias musicales que relacionan a este famoso rey con la música se encuentran entre las más importantes y extensas de cuantas existen en el corpus isidoriano.

52 "La música aplaca los ánimos excitados, como se lee en David, quien por medio del arte musical, liberó a Saúl del espíritu inmundo".

53 "Así se lee de David, que liberó a Saúl del espíritu inmundo sirviéndose de la música".

54 "Cuando todavía era un joven que tocaba dulce pero vigorosamente la cítara, sometió al espíritu demoníaco que poseía a Saúl, no porque fuese tan elevado el poder de su cítara, sino porque la figura de la cruz de Cristo estaba proyectada místicamente en la madera y la tensión de las cuerdas, de modo que fue la Pasión misma lo que se interpretó, y eso sometió al espíritu del demonio". cum sensus iudaeorum per blasphemiam in furorem vertitur, dignum est ut ad salutem mentes eorumn quasi dulcedine citharae, locutionis evangelicae tranquillitate revocentur. ${ }^{55}$

Existen varios ejemplos conservados en la literatura clásica sobre este tipo de curaciones de carácter un tanto más milagroso a través de la música. En ellos suelen aparecer famosos músicos griegos, especialmente de la época arcaica o del período inmediatamente siguiente; las fuentes literarias posteriores hacen referencia a esas épocas - sobre todo la primera, el período arcaico - con una mezcla de historicismo y leyenda. Entre estos famosos músicos de la época arcaica destacan Terpandro de Lesbos ${ }^{56}$ y Taletas de Gortina, ${ }^{57}$ quienes son descritos realizando curaciones "milagrosas" a través de la música. No obstante, también existen ejemplos de este tipo de curaciones algo posteriores, tal y como ocurre con los mencionados casos de

55 “1. Después aumentó de tal manera el odio de Saúl hacia David, que el rey intentó clavarlo con una lanza cuando cantaba como de costumbre para curar su espíritu. Porque mientras el espíritu maligno invadía a Saúl, David, cítara en mano, curaba su locura. 2. Saúl representa el orgullo de los judíos, David, la humildad de Cristo. Cuando Saúl es poseído por el espíritu inmundo y David canta, su locura es curada, porque cuando la mente de los judíos se vuelve delirante por la blasfemia, es conveniente que se las devuelva a la salud mediante el sosiego de la palabra evangélica así como por la dulzura de la cítara".

${ }^{56}$ Ateneo de Náucratis $(14.37,635 \mathrm{~d}-\mathrm{e})$ recoge algunas noticias de fuentes secundarias sobre la cronología de Terpandro de Lesbos. Pasó gran parte de su vida en Esparta, ciudad en la que, según Filodemo (Phld.Mus.4. pp. 18 y 86-89, Kemke), se convirtió en una institución, y en la que, según Plutarco (Mor.Mus.1146B), llegó a reconciliar a través de su música a algunos grupos de ciudadanos enfrentados en una guerra civil. Además, hay que destacar que fue vencedor de algún festival musical de las Fiestas Carneas entre los años 676 y 673 a. C., victoria recogida por Ateneo (14.37, 635d-e). Según Plutarco (Mor.Mus.1132C), Terpandro fue el creador del nomo citaródico y un excepcional compositor del mismo, poniendo música tanto a sus propios hexámetros como a los de Homero. A su vez, se le atribuye la invención de la lira de siete cuerdas (Arist.Pr.19.32, Plut.Mor.Mus.1140F, Ath.14.37.635d-e, Plin. HN.7.204) y del bárbitos (Ath.4.77, 175e), lira con un sonido más grave debido a la mayor longitud de sus cuerdas y brazos.

${ }^{57}$ Taletas de Gortina fue un aedo y músico procedente de Gortina (Creta) que desarrolló su carrera en Esparta durante el siglo VII a. C., llegando a ser amigo del legislador espartano Licurgo (Plut.Vit.Lyc.4.23). En dicha ciudad desarrolló el peán y el hiporquema, composición musical dedicada a Apolo acompañada de una danza que también recibía el mismo nombre (en relación al hiporquema, Luc.Salt.16.1-7), a su vez acompañada de la forminge $\mathrm{y}$, posteriormente, del aulos y la cítara o la lira (Poll.4.82.2-3). Taletas es considerado miembro de la segunda escuela de música de Esparta (la cabeza de la primera fue Terpandro) junto a Jenócrito, Jenodamo, Sácadas y Polimnesto, siendo también uno de los creadores de las Gimnopedias en el 665 a. C. (Plut.Mor. Mus.1134B-E), fiestas en honor a Apolo consideradas como las más importantes de los lacedemonios en las que los efebos desnudos ejecutaban danzas en honor al dios. La grandeza de la música de Taletas era tal que, según Plutarco (Mor.Mus.42.1146B-C), en una ocasión llegó a librar de la peste a la ciudad de Esparta. 
Pitágoras (Iamb.VP.25), principalmente, de Empédocles (Iambl.VP.25 - no mencionado anteriomente- $)^{58}$ o de Damón (Gal.5.473 -Kühn-).

El pasaje de la curación de David a Saúl a través de la música (1Re.16.14-23) constituye el único de toda la Biblia en el que aparecen las propiedades curativas, salutíferas o liberadoras de la música de una manera tan clara, aunque en otros pasajes se puede observar cómo la música ayuda a alcanzar a los profetas sus trances o su inspiración..$^{59}$ Esto nos hace pensar que todos estos relatos relacionados con los poderes medicinales de la música fuesen algo común no solo en el mundo grecolatino, sino en otras culturas minoritarias ubicadas en el arco mediterráneo oriental y el Medio Oriente, tal y como ocurre con los relatos sobre los inventores o descubridores de la música como Jubal, Pitágoras, los dioses y héroes míticos paganos, todos ellos referenciados por el propio Isidoro en diferentes lugares de su obra.

Por otro lado, es importante señalar la verdadera finalidad del pasaje de la curación de David a Saúl, que, en palabras de Samuel Pagán, no es mostrar las habilidades musicales de David, sino contrastar las personalidades de Saúl y David: "Un rey que debería ser poderoso, fuerte y seguro, pero que se mostraba ansioso, inseguro y débil; y un joven sin experiencia militar, que con su música manifestaba seguridad, sobriedad y fortaleza" ${ }^{60}$ No obstante, y teniendo en cuenta el objetivo de este trabajo, considero que se debe profundizar todavía más, pues resulta paradójico que sea David - que es quien causa todas estas inseguridades, celos y complejos a Saúl - quien tenga que curar al rey. Esto nos conduce a un aspecto muy importante: situar el origen de la ciencia musical y médica de David, que es lo que, a mi juicio, diferencia fundamentalmente este caso de los anteriores, pertenecientes a la tradición clásica grecolatina.

En el caso de David sus conocimientos de meloterapia ya no proceden de la reflexión científica, tal como ocurre con Asclepíades y la larga tradición filosófica y científica en la que se

${ }^{58}$ Empédocles (484/481-424/421) fue uno de los más grandes físicos pluralistas. Reformuló la explicación eleática del ser y el no ser expuesta por Parménides partiendo de una pluralidad de principios: los famosos aire, agua, tierra y fuego. Jámblico (VP.25) cuenta cómo Empédocles curó a través de la música a un joven iracundo y fuera de sí que trataba de asesinar a un juez con una espada. Empédocles, viendo la situación y el estado del joven, cogió su lira e interpretó unos versos de Homero (Od.4.221) con una melodía tranquilizadora en el modo idóneo, curando inmediatamente al joven. Aunque este relato constituye un ejemplo más de estos relatos de curaciones de carácter milagroso que vengo exponiendo, lo cierto es que la influencia de la música en el hombre podría fundamentarse desde la teoría del conocimiento que defiende el propio Empédocles (aspecto que nunca hizo): los efluvios de los cuatro elementos que se liberan de la música influirían en los elementos semejantes que existen en el hombre.

59 Véase $4 R e .3 .15$, donde la música inspira a Eliseo, y $1 R e .10 .1-6$, fragmento en el que, por boca de Samuel, varios profetas sin identificar aparecen profetizando acompañados por la música.

${ }^{60}$ Samuel Pagán, El rey David: una biografía no autorizada (Viladecavalls, Barcelona: Clie, 2013), p. 26. asientan. Tampoco son fruto de sus habilidades musicales que, evidentemente, las tiene - como ocurre con los casos de Terpandro, Taletas o Pitágoras, quien también fue un gran músico práctico. En el caso de David, tal y como también reflejan claramente los fragmentos citados de las Cuestiones isidorianas, sus habilidades musicales y médicas proceden de Dios, pues Dios es quien castiga y causa los males a Saúl y Dios es quien elige a David para curarlo (1Re.16.12-13). Por tanto, el poder medicinal y musical de David es una manifestación del poder de Dios. Esta es la justificación y la finalidad teológica del fragmento bíblico de la curación de Saúl a través de la música de David. Es un aspecto que considero muy importante para que los escritores cristianos posteriores que tratan estos temas relacionados con la música y la medicina - entre los que se encuentra Isidoro - se hagan eco de esta noticia y la expongan en sus textos. Por tanto, para Isidoro la música cura - en este caso a Saúl - porque es una manifestación más del poder y la grandeza de Dios.

Si seguimos a James Mckinnon podemos observar un nutrido grupo de escritores cristianos que recogen y tratan esta noticia: ${ }^{61}$ Clemente de Alejandría (Prot .1.5.2-4), ${ }^{62}$ Atanasio de Alejandría (Ep.Marc.29), ${ }^{63}$ Basilio de Cesarea (Gent.7), ${ }^{64}$ Teodoreto de Ciro (H.E.3.19.1-4) ${ }^{65}$ y Nicetas de Remesiana (Ut. Hymn.3-4), ${ }^{66}$ a los que habría que añadir Casiodoro (Inst.2.5.8).

${ }^{61}$ James Mckinnon, Music in Early Christian Literature (Cambridge: Cambridge University Press, 2012), pp. 30, 53, 69, 104-105 y 135.

${ }^{62}$ Clemente de Alejandría (ca. 150-211/215) es, junto con Orígenes (185-254), la cabeza más visible de la escuela catequética de Alejandría. El pensamiento de Clemente busca un equilibrio entre la fe y la filosofía, ya que trata de profundizar en la fe - según Clemente, principio y fundamento de la filosofía - con la ayuda de la razón y el conocimiento.

${ }^{63}$ Atanasio de Alejandría (ca. 296-373), gran conocedor de la doctrina cristiana, fue obispo de dicha ciudad y uno de los más firmes defensores de la consustancialidad del Padre y del Hijo ante la doctrina arriana en el Concilio de Nicea (325), conviritiéndose, a la postre, en el gran vencedor del Concilio y en uno de los más firmes defensores de sus cánones a lo largo de toda su vida, especialmente ante el paganismo y, sobre todo, el arrianismo.

${ }^{64}$ Basilio de Cesarea o Basilio el Grande (331-379) fue natural y obispo de dicha ciudad. Es uno de los cuatro grandes padres de la Iglesia griegos del siglo IV junto a su hermano Gregorio de Nisa y Gregorio de Nacianzo, con quienes forma el grupo de los llamados padres capadocios, y Atanasio de Alejandría. La principal aportación de los padres capadocios consistió en la fundamentación de la cultura y la religión cristiana a través de la recopilación y utilización de lo mejor y lo más salvable de la cultura clásica. Esta cultura y religión cristianas alcanzaron gracias a sus trabajos y logros una profundidad y amplitud no conocidas hasta el momento.

${ }^{65}$ Teodoreto de Ciro (que vivió en el siglo V), obispo de dicha ciudad, es considerado el último gran teólogo de la escuela de Antioquía; de una elevada formación clásica y cristiana, sus escritos de carácter histórico, polémico, apologético y doctrinal son especialmente importantes.

${ }^{66}$ Nótese que Mckinnon habla de una obra denominada De utilitate hymnorum, que es más conocida como De psalmodiae bono, anterior- 
Los escritores cristianos que trataron estos temas musicales y médicos tuvieron aquí un paralelo judeocristiano que contraponer a los ejemplos de la rica tradición grecolatina y no dudaron en utilizarlo. Al igual que ocurre en otras ocasiones a lo largo de la obra isidoriana, en esta ocasión el doctor hispalense recoge esta noticia bíblica consciente de la importancia de situar la cultura judeocristiana a un nivel superior o, al menos, al mismo nivel que la cultura grecolatina. Este aspecto es una constante que se repite en otras muchas obras de Isidoro y de otros escritores cristianos tardoantiguos que trataron de relacionar o "conciliar" aspectos de ambas culturas, la judeocristiana y la pagana, aunque siempre, si la situación lo permite, supeditando los aspectos de la cultura pagana a la cristiana. ${ }^{67}$

A pesar del origen bíblico de la historia y de que Isidoro evidentemente lo conocía, el obispo hispalense utiliza autores tardoantiguos como fuentes para sus textos, copiándolos prácticamente al pie de la letra en la mayoría de los casos, pudiéndose observar nuevamente las dos vías que señalé en el primer apartado: la de origen pagano - que en este asunto tiene un valor mínimo, tal y como demostraré- y la cristiana.

La fuente utilizada para el pasaje de Etym.3.16.3 se encuentra, una vez más, en Casiodoro, donde se observa un texto que es copiado casi al pie de la letra. La primera parte del texto de Etym.3.16.3 ("Excitos quoque animos musica sedat") está inspirada, de forma casi literal pues la terminología es la misma, en la última parte de una reflexión que Casiodoro atribuye a Varrón en Inst.2.5.8: "In quibus [refiriéndose a los modos musicales que ha explicado anteriormente], ut Varro meminit, tantae utilitatis

mente citada con esta denominación; de hecho, así es como aparece en la $P L$ (v. 68 , cols. 371-376).

${ }^{67}$ El interés por conciliar la cultura pagana y la judeocristiana se repite en otros tantos lugares de la obra isidoriana, entre los que destaca su tratado Sobre el universo, con las distintas explicaciones de fundamentación cristiana que va dando $-\mathrm{y}$ tratando de conciliar con las paganas - a cada uno de los fenómenos astronómicos expuestos que ya gozaban de una explicación científica pagana en la rica tradición que sobre este tema se desarrolló en la literatura anterior grecolatina. Además, esta intención se observa en otros puntos concretos de su obra como Etym.1.39.11, donde trata el origen del hexámetro, Etym.1.39.18, donde comenta el origen de los epitalamios, Etym.1.39.19, donde expone el origen de los trenos, Etym.1.42.1, donde trata el origen de la historia, o el mismo Etym.3.15.1, donde expone el origen de la música. Para el interesante caso del origen de la música, véase José María Diago Jiménez, "El origen judeocristiano de la música en la obra de Isidoro de Sevilla", Cuadernos de música iberoamericana, 32 (2019), pp. 13-29.

${ }^{68}$ Varrón (116-27 a. C.) fue el más grande erudito y anticuario romano. Es uno de los grandes bastiones latinos en algunos de los más importantes campos del saber clásico, entre los que destacan las llamadas artes o disciplinas liberales, materia sobre la que escribió nueve libros, Disciplinarum Libri IX, obra fundamental - de la que no se ha conservado nada y de la que solo se sabe a través de fuentes secundarias - en todo lo relacionado con la asimilación y el desarrollo del enciclopedismo clásico en el mundo antiguo. virtus ostensa est ut excitatos animos sedarent". ${ }^{69}$ Por tanto, aunque su fuente inmediata sea Casiodoro, se puede observar nuevamente una influencia claramente pagana, cuyo origen se puede remontar al pitagorismo y platonismo antiguo. No obstante, su valor es mínimo, pues se trata tan solo de una expresión.

\begin{tabular}{|l|l|}
\hline \multicolumn{1}{|c|}{ ISIDORO } & \multicolumn{1}{c|}{ CASIODORO } \\
\hline $\begin{array}{l}\text { Excitos quoque animos } \\
\text { musica sedat }\end{array}$ & $\begin{array}{l}\text { In quibus [refiriéndose a los } \\
\text { modos musicales que ha } \\
\text { explicado anteriormente], ut } \\
\text { Varro meminit, tantae } \\
\text { utilitatis virtus ostensa est ut } \\
\text { excitatos animos sedarent }\end{array}$ \\
\hline
\end{tabular}

Sin embargo, se observa cómo la segunda parte de texto de Etym.3.16.3 y la segunda parte del texto de Etym.4.13.3 son copiadas también prácticamente al pie de la letra de Casiodoro (Inst .2.5.9):

quid de David dicimus, qui ab spiritibus immundis Saulem disciplina saluberrimae modulationis eripuit, novoque modo per auditum sanitatem contulit regi, quam medici non poterant herbarum potestatibus operari? [...] multa sunt autem, quae in aegris hominibus per hanc disciplinam leguntur facta miracula. ${ }^{70}$

Si simplificamos el texto de Casiodoro obtenemos el siguiente cuadro compartivo con los dos fragmentos isidorianos -iguales entre sí salvo por el añadido de Etym.3.16.3 comentado en el cuadro anterior - y el texto de Casiodoro. Se puede apreciar cómo coinciden palabra por palabra. En este caso es difícil precisar si Casiodoro, autor cristiano, se basa en una fuente anterior; fuente que, en cualquier caso, ya sería cristiana.

\begin{tabular}{|c|c|c|}
\hline $\begin{array}{c}\text { ISIDORO } \\
(\text { Etym.3.16.3) }\end{array}$ & $\begin{array}{c}\text { ISIDORO } \\
(\text { Etym.4.13.3) }\end{array}$ & $\begin{array}{l}\text { CASIODORO } \\
\text { (Inst.2.5.9) }\end{array}$ \\
\hline $\begin{array}{l}\text { sicut de David } \\
\text { legitur, qui a } \\
\text { spiritu inmundo } \\
\text { Saulem arte } \\
\text { modulationis } \\
\text { eripuit }\end{array}$ & $\begin{array}{l}\text { sicut de David } \\
\text { legitur, qui ab } \\
\text { spiritu inmundo } \\
\text { Saulem arte } \\
\text { modulationis } \\
\text { eripuit }\end{array}$ & $\begin{array}{l}\text { quid de David } \\
\text { dicimus, qui ab } \\
\text { spiritibus } \\
\text { immundis Saulem } \\
\text { disciplina } \\
\text { saluberrimae } \\
\text { modulationis } \\
\text { eripuit }\end{array}$ \\
\hline
\end{tabular}

\footnotetext{
69 "En ellos se pone de manifiesto - como recuerda Varrón - un valor de tanta utilidad que puede apaciguar los ánimos excitados".

70 “QQué podemos decir de David, el cual arrebató a Saúl de los espíritus inmundos mediante la muy saludable disciplina del arte musical, confiriendo al rey a través del oído la salud que no habían podido brindarle los médicos con los poderes de las hierbas? [...] Muchos son pues los hechos recogidos como milagros en personas enfermas gracias a esta disciplina".
} 
Por su parte, el parágrafo 9.4 del comentario al Primer Libro de los Reyes de las Cuestiones sobre el Antiguo Testamento está prácticamente copiado al pie de la letra de un fragmento (capítulo 1) de una obra de Nicetas de Remesiana, concretamente De psalmodiae bono. Se puede apreciar también cómo llegan estas ideas a Isidoro cristianizadas, pues se observa cómo Isidoro establece una relación de carácter alegórico entre la música de David - que representa la música de las esferas cristianizada, la música de Dios - con el poder de Dios.

\begin{tabular}{|c|c|}
\hline ISIDORO & NICETAS \\
\hline $\begin{array}{l}\text { Iste adhuc puer in cithara } \\
\text { suaviter, into fortiter canens, } \\
\text { malignum spiritum, qui } \\
\text { operabatur in Saule, } \\
\text { compescuit, non quod } \\
\text { citharae illius tanta virtus } \\
\text { erat, sed quod figura crucis } \\
\text { Christi, quae de ligno et } \\
\text { extensione nervorum mystice } \\
\text { gerebatur, ipsaque passio, } \\
\text { quae cantabatur, iam tunc } \\
\text { spiritus daemonis } \\
\text { opprimebat }\end{array}$ & $\begin{array}{l}\text { Qui adhuc puer in cithara } \\
\text { suauiter fortiterque canens, } \\
\text { malignum spiritum qui } \\
\text { operabatur in Saule, } \\
\text { compescuit : non quo } \\
\text { citharae illius tanta uirtus } \\
\text { erat, sed quia figura cricis } \\
\text { Christi, quae in ligno et } \\
\text { extensione neruorum mystice } \\
\text { gerebatur, iam tunc spiritum } \\
\text { daemoni opprimebat. }\end{array}$ \\
\hline
\end{tabular}

La relación alegórica es establecida entre la música y la cítara de David con la cruz de Cristo que, a su vez, representa su "Pasión misma" ("ipsa passio" en palabras del propio Isidoro) y, en última instancia, la salvación a través de la Resurrección, es decir, la esencia del cristianismo. De hecho, Isidoro llega a indicar - evidentemente, con un claro sentido metafórico- que David lo que realmente interpreta musicalmente es la misma Pasión de Cristo, siendo eso lo que verdaderamente venció al demonio que poseía a Saúl. La música de David, el poder de Dios, vence al mal, representado por el espíritu diabólico que posee a Saúl.

Por ultimo, hay que destacar que los dos parágrafos que constituyen el capítulo 12 de ese mismo comentario perteneciente a las Cuestiones sobre el Antiguo Testamento podrían estar copiados, prácticamente al pie de la letra, de un fragmento del capítulo 19 del comentario al Primer Libro de los Reyes nótese que se trata también de un comentario al mismo libro bíblico - que se ha venido atribuyendo con muchas dudas a Euquerio de Lyon hasta hace bien poco. ${ }^{71} \mathrm{Si}$ ponemos ambos

${ }^{71}$ Euquerio de Lyon fue un autor cristiano que vivió en la primera mitad del siglo V. Compuso una serie de obras que la crítica le atribuye unánimemente. Sin embargo, tradicionalmente se le han atribuido otras que ofrecen serias dudas, siendo, a menudo, su autoría descartada. Entre estas últimas obras se encuentra la citada en el cuerpo del texto: Comentario a los cuatro libros de los reyes, obra que es atribuida por Machielsen a un autor posterior al propio Isidoro, opinión más aceptada por la crítica a día de hoy; de ahí que no se pueda afirmar con rotundidad que Isidoro haya leído y copiado este texto de Euquerio de Lyon. Véase Io- textos en cuadro comparativo se puede observar que, si exceptuamos una sola palabra (un error), son prácticamente iguales.

\begin{tabular}{|c|c|}
\hline ISIDORO & EUQUERIO \\
\hline $\begin{array}{l}\text { Auxit deinde odium Saul } \\
\text { adversus David in tantum, ut } \\
\text { rex ad medetam sui spiritus } \\
\text { David de more psallentem } \\
\text { iaculo conaretur configere. } \\
\text { Sed quid est, quod dum } \\
\text { Saulem spiritus adversus } \\
\text { invaderet, apprehensa David } \\
\text { cithara, eius vesaniam } \\
\text { mitigabat? Per Saulem enim } \\
\text { Iudaeorum elatio, per David } \\
\text { autem humilitas Christi } \\
\text { significatur. Cum ergo Saul } \\
\text { ab immundo spiritu arripitur, } \\
\text { David canente, eius vesania } \\
\text { temperatur, quia cum sensus } \\
\text { iudaeorum per blasphemiam } \\
\text { in furorem vertitur, dignum } \\
\text { est ut ad salutem mentes } \\
\text { eorumn quasi dulcedine } \\
\text { citharae, locutionis } \\
\text { evangelicae tranquillitate } \\
\text { revocentur }\end{array}$ & $\begin{array}{l}\text { Auxit deinde odium Saul } \\
\text { adversus David in tantum ut } \\
\text { rex ad medelam sui spiritus. } \\
\text { David de more psallentem } \\
\text { iaculo conaretur configere. } \\
\text { Sed quid est quod dum } \\
\text { Saulem spiritus adversus } \\
\text { invaderet, apprehensa David } \\
\text { cithara, eius vesaniam } \\
\text { mitigabat? Per Saulem enim } \\
\text { Iudaeorum elatio, per David } \\
\text { autem humilitas Christi } \\
\text { significatur. Cum ergo Saul } \\
\text { ab immundo spiritu arripitur, } \\
\text { David canente, eius vesania } \\
\text { temperatur, quia cum sensus } \\
\text { iudaeorum per blasphemiam } \\
\text { in furorem vertitur, dignum } \\
\text { est ut ad salutem mentes } \\
\text { eorumn quasi dulcedine } \\
\text { citharae, locutionis } \\
\text { evangelicae tranquillitate } \\
\text { revocentur }\end{array}$ \\
\hline
\end{tabular}

En este fragmento se observa cómo David hace recobrar la salud a Saúl gracias al canto de la palabra evangélica, o, dicho de otro modo, gracias a la interpretación de algún salmo. Sin embargo, la música que interpreta David vuelve a ser una alegoría, en este caso de la humildad de Cristo (humilitas Christi), quien, aun siendo hijo de Dios, se sacrificó por la salvación de

hannes Machielsen, Clavis Patristica Pseudoepigraphorum Medii Aevi, 4 vols. (Turnhout: Brepols, 1994), IIA, nº 2188.

Por otra parte, es preciso indicar que Gregorio Magno también comenta este pasaje del Primer Libro de los Reyes en el capítulo 25 de su Regla Pastoral. Sin embargo, a pesar de la influencia que Gregorio ejerció sobre Isidoro y otros autores hispanos -y de que Isidoro conocía con profundidad esta obra gregoriana y, además, en el prólogo de sus Cuestiones cita a Gregorio como una de sus fuentes-, si se comparan los fragmentos de estos dos padres de la Iglesia no se observa una relación lo suficientemente estrecha como para poder afirmar que Isidoro utiliza como fuente a Gregorio. Además de las evidentes diferencias de carácter léxico, hay que destacar que el texto de Gregorio es una especie de resumen del texto de Isidoro, cuando generalmente lo que suele ocurrir es lo contrario: que Isidoro copie o condense las ideas de Gregorio. El fragmento de Gregorio es bastante más corto y no comenta todas las ideas que se pueden leer en el texto del obispo hispalense. Por tanto, teniendo en cuenta estas apreciaciones también resulta difícil afirmar una posible fuente o influencia gregoriana. 
la humanidad. ${ }^{72}$ Nuevamente estamos hablando de una alegoría del poder y la grandeza de Dios. La música de David es la metáfora del poder de Dios y representa la fuerza de este. David cura a Saúl gracias al poder de Dios. Por tanto, para la correcta comprensión de estos últimos dos textos, ha de considerarse siempre el punto de vista alegórico; es decir, la referencia implícita o explícita al plano metafísico de la harmonía de las esferas, música acústica y metafísica que, ejemplificada en la música de David, es para Isidoro una alegoría de la perfección del universo que, a su vez, representa el poder y la grandeza de Dios y su obra.

\section{LA MELOTERAPIA EN LA HISPANIA VISIGODA}

Por último, antes de concluir, es necesario realizar un breve repaso a los posibles usos de la meloterapia en la Hispania visigoda para tener un panorama completo del verdadero lugar que ocupan estas teorías en el pensamiento musical isidoriano. $\mathrm{Si}$ revisamos las fuentes escritas hispanovisigodas, no es difícil afirmar con cierta rotundidad que en la Hispania visigoda no se practicó la meloterapia.$^{73}$ No existe ningún testimonio que nos hable de manera explícita de la utilización médica de la música en el reino hispanovisigodo, por lo que, en principio, hay que descartar estas prácticas. Tampoco existen textos médicos con cierta entidad - si exceptuamos el Libro IV de las Etimologías - que nos hagan pensar no solo en el desarrollo de estas prácticas, sino, incluso, en el conocimiento de su existencia y su desarrollo en épocas anteriores. Es más, si hacemos caso a los pocos textos existentes en la legislación visigoda que hacen referencia a la práctica de la medicina - fundamentalmente algunas leyes del Código de Eurico-, se puede observar que la figura del médico está bastante desprestigiada. ${ }^{74}$ Estas leyes dan a en-

\footnotetext{
${ }^{72}$ Ha de notarse el carácter antijudaico que tiene el fragmento, repetido en otras obras isidorianas como Sobre la fe católica contra los judios. Este hecho responde a una realidad de la Hispania visigoda. Para una aproximación a esta cuestión, con dos puntos de vista diferentes, pueden verse Laureano Castán Lacoma, "San Isidoro, apologista antijudaíco", en Manuel C. Díaz y Díaz, Isidoriana. Colección de estudios sobre san Isidoro de Sevilla en el XIV centenario de su nacimiento (León: Centro de Estudios San Isidoro, 1961), pp. 445-456; y Ursifino Dominguez del Val, Historia de la Antigua Literatura Latina Hispano-cristiana. Tomo II. Siglos IV y V (Madrid: Fundación Universitaria Española, 1998), pp. 119-121.

${ }^{73}$ Recuérdese que no hablamos del uso terapéutico de la palabra, como puede ser un exorcismo.

${ }^{74}$ No obstante, esta afirmación ha de matizarse, pues no en toda la literatura hispanovisigoda aparece esta visión del médico, ya que dentro de las élites minoritarias ilustradas se observa alguna excepción. Ejemplo característico y conocido es el del famoso obispo emeritense Paulo, de origen griego y médico de profesión, quien ejerció una conocida curación a una mujer encinta. Del mismo modo, también es de destacar la atención que dedican algunas reglas monásticas hispanovisigodas, como la de Isidoro o la Regla de los Abades, a velar por el cuidado de los enfermos (véanse los capítulos VII de la primera y XXII de la segun-
}

tender que era bastante frecuente que los pacientes no pagasen a los médicos por sus servicios, no sólo cuando los médicos fallaban en sus curaciones, cosa que debía ser bastante frecuente si la dolencia era grave, sino, incluso, cuando acertaban y el paciente mejoraba. Entonces también era frecuente que el paciente sanado se olvidase de pagar al médico, situación que no solo ocurría con los pacientes pobres, ya que también se daba entre los pacientes ricos. ${ }^{75}$ Incluso el propio Isidoro en sus Versos parece corroborar esta situación del médico; véanse al respecto los poemas XVII y XVIII. ${ }^{76}$ Por tanto, todo hace pensar que la meloterapia fue una gran desconocida en la Hispania visigoda.

\section{CONCLUSIONES}

Que la meloterapia no se desarrollase en la Hispania visigoda no es óbice para considerar que el obispo hispalense no creyera en la eficacia de estas prácticas desde su profunda visión cristiana de la realidad, aun teniendo en cuenta las escasas noticias que expone en su obra; bases para creer en ello, desde luego, tenía.

Los fundamentos filosófico-musicales de la meloterapia que el doctor hispalense expuso en diferentes lugares de su obra llegaron a Isidoro a través de dos vías principales, la de origen pagano - cimentada en principios de origen pitagórico y platónico, leídos fundamentalmente en Quintiliano y, en menor medida, Casiodoro-, que recogió como enciclopedista (Etym.3.16.1 y Etym.3.22.2); y la puramente cristiana - cimentada en principios sólidamente cristianos, leídos en Agustín y Nicetas de Remesiana, que partían de otros anteriores de origen pitagórico y platónico-, que recogió como padre de la Iglesia y enciclopedista (Quaest.in I Reg.9.3-4).

A través de estos fundamentos, especialmente a través de su asimilación cristiana, Isidoro pudo cimentar las reflexiones sobre la meloterapia que expuso en diferentes lugares de su obra (Etym.3.16.3, Etym.4.4.1, Etym.4.13.3, Quaest.in I Reg.9.4 y Quaest.in I Reg.12), basándose o copiando a diversos autores tardoantiguos que representan lo más genuino de esas dos tradiciones musicales señaladas: la pagana, representada por Casio-

da). No obstante, en ninguna de estas reglas aparece absolutamente nada sobre la figura del médico o sobre aspectos de carácter medianamente técnico - teniendo en cuenta la ciencia de la época o el contenido del Libro IV de las Etimologías - concernientes a la medicina.

${ }^{75}$ Tan solo una de las leyes del Código de Eurico protege levemente la figura del médico; véase Isidorus Hispalensis Ethymologiarum Liber IIII. De Medicina (Barcelona: Laboratorios del Norte de España, 1945), pp. 9-16.

${ }^{76}$ Es de destacar que el conjunto de poemas XVI-XXIV de sus Versos está relacionado con la medicina y la farmacopea, por lo que, siguiendo la teoría de Fontaine (ISCC, pp. 736-762), es muy probable que estos versos fuesen un indicador de la existencia de varios armarios de su biblioteca dedicados a la ciencia médica, contando con libros y materiales necesarios para elaborar el Libro IV de las Etimologías. Del mismo modo, y siguiendo nuevamente esta teoría, quizá estos armarios también fuesen el lugar donde se guardasen los fármacos. 
doro, autor cristiano que, debido a su faceta de enciclopedista, también basa parte de sus reflexiones en fuentes paganas anteriores como Censorino y Capela; y la cristiana, representada por Casiodoro, Nicetas y, quizás, Euquerio de Lyon.

Por otra parte, los ejemplos de curaciones concretas que el doctor hispalense expone en su obra, que también gozaron de un riquísimo acervo cultural y literario en la Antigüedad, debieron ser para Isidoro argumentos muy importantes para poder comprobar que estas utilidades de la música se practicaron en épocas anteriores. Entre estos ejemplos hay que destacar los dos últimos que hemos presentado. A través del ejemplo de Asclepíades de Bitinia pudo comprobar que estas prácticas pudieron ser algo común en el pasado, siendo, además, objeto de fundamentación científica al ser practicadas por hombres doctos, en este caso un hombre muy ilustre y respetado en la rama de la medicina. El ejemplo de la curación de David a Saúl tiene todavía mayor importancia, pues, gracias a los textos que pudo leer en las obras de Nicetas y, quizás, Euquerio, el obispo hispalense descubrió de primera mano algunas pinceladas del fundamento filosófico-musical cristiano - en su mayor parte de carácter alegórico - de estas prácticas musicales curativas recogidas también en la Biblia y amparadas por su autoridad, que, en esencia, refuerzan el poder de Dios y la concepción cristiana del universo.

Por tanto, aunque es difícil precisar qué pudo opinar realmente Isidoro sobre el uso terapéutico de la música en la vida cotidiana, considero que lo más probable es que debió tener la verdadera convicción de que estos usos de la música eran posibles y tenían su efecto, siempre y cuando se hicieran, además de con los conocimientos técnicos apropiados - desconocidos para él-, desde la fe más profunda. Volviendo a esta bella idea que ha ido apareciendo varias veces a lo largo del artículo, para Isidoro, la música puede curar al hombre porque la música es obra de Dios, como lo es también el propio hombre y el resto del universo. Para Isidoro, la harmonía de las esferas de los antiguos regida por el número es la harmonía del universo creado y regido por Dios.

\section{BIBLIOGRAFÍA CITADA}

Abert, Hermann. Die Lehre von Ethos in der grieschischen Musik. Leipzig: Breitkopf \& Härtel, 1899.

Anderson, Warren D. Ethos and Education in Greek Music. The evidence of poetry and philosophy. Cambridge, MA: Harvard University Press, 1966.

Barker, Andrew. Greek Musical Writings, 2 vols. Cambridge: Cambridge University Press, 1984.

- Psicomusicologia nella Grecia Antica, editado por Angelo Meriani. Nápoles. Guida, 2005.

Burkert, Walter. Lore and Science in Ancient Pythagoreanism. Cambridge, MA: Harvard University Press, 1972.

Carone, Gabriela Roxana. Plato's Cosmology and its ethical dimensions. Cambridge: Cambridge University Press, 2005.
Castán Lacoma, Laureano. "San Isidoro, apologista antijudaíco". En Isidoriana. Colección de estudios sobre san Isidoro de Sevilla en el XIV centenario de su nacimiento, editado por Manuel C. Díaz y Díaz. León: Centro de Estudios San Isidoro, 1961, pp. 445-456.

Cerqueira, L. M. G. “A música especulativa nas Etymologiae de Isidoro de Sevilha". Modus, 6 (2006), pp. 143-179.

Cornford, Francis M. Plato's Cosmology. Londres: Hackett Publishing Company, 1971.

Correa Pavón, Guillermo León. Numerus-proportio en el De Musica de san Agustin (Libros I y VI). La tradición pitagórico-platónica. Tesis doctoral, Universidad de Salamanca, 2009.

Diago Jiménez, José María. "El origen judeocristiano de la música en la obra de Isidoro de Sevilla". Cuadernos de música iberoamericana, 32 (2019), pp. 13-29.

Diels, Hermann, y Walther Kranz. Die Fragmente der Vorsokratiker. Griechisch und Deutsch, 3. vols. Dublin y Zurich, 1975.

Dominguez del Val, Ursifino. Historia de la Antigua Literatura Latina Hispano-cristiana. Tomo II: siglos IV y V. Madrid: Fundación Universitaria Española, 1998.

Ferraces Rodríguez, Arsenio, ed. Isidorus medicus. Isidoro de Sevilla y los textos de medicina. A Coruña: Universidade da Coruña, 2005.

Fidalgo Díaz, María Nieves. Censorino. El libro del cumpleaños, traducción y notas. Prólogo de Carlos García Gual. Madrid: Alba Editorial, 2008.

Figari, Joël. La philosophie pythagoricienne de la musique. París: Université de Paris IV Sorbonne, 2002.

_. "Musique et médicine dans la philosophie présocratique". En Musique \& Antiquité. Actes du colloque d'Amiens, editado por Odile Mortier-Waldschmidt. París: Les Belles Lettres, 2006, pp. 121-145.

Fontaine, Jacques. Isidore de Seville et la culture classique dans L'espagne wisigothique. París: Études Augustiniennes, segunda edición revisada y corregida, 1983.

Gasparotto, Giovanni, y Jean-Yves Guillaumin. Isidorus Hispalensis. Etymologiae III, texte établi par G. Gasparotto, traduit et commenté par J.-Y. Guillaumin. París: Les Belles Lettres, Auteurs latins du Moyen Âge, 2009.

Gil Fernández, Luis. Therapeia. La medicina popular en el mundo clásico. Madrid:

Triacastela, 2004.

Green, Robert Montraville. Asclepiades. His life and writings. New Haven, CT: Elizabeth Licht, 1955.

Gowdin Joscelyn. Armonía de las esferas. Gerona: Atalanta, 2009.

Hispalensis Ethymologiarum Liber IIII. De Medicina. Barcelona: Laboratorios del norte de España, 1945.

Hornblower, Simon, Antony Spawforth, et al, eds. Oxford Classical Dictionary. Oxford: Oxford University Press, 2012.

Huglo, Michel. "La tradición de la Musica Isidori en la Península Ibérica". En Hispania Vetus. Manuscritos litúrgico-musicales de los orígnes visigóticos a la transición franco- 
rromana (siglos IX-XII), editado por Susana Zapke. Bilbao: Fundación BBVA, 2007, pp. 61-93.

Jan, K. v. "Die Harmonie der Shpären". Philologus, 52 (1894), pp. 13-37.

Jones, Joseph R. "Isidore and the Theater". Comparative Dra$m a, 16 / 1$ (1982), pp. 26-48.

Lindsay, W. M. Isidori Hispalensis Episcopi Etymologiarum sive Originum libri $X X$, recognovit brevique adnotatione critica instruxit, 2 vols. Oxford: Oxford Classical Texts, 1971.

León Tello, Francisco José. "La teoría musical en las obras de Isidoro de Sevilla". Música. Revista Trimestral de los Conservatorios Españoles, 1 (1952), pp. 11-28.

Luque Moreno, Jesús. "Letras, notas y estrellas. $1^{\text {a }}$ Parte". MHNH. Revista internacional de investigación sobre magia y astrología antiguas, 11 (2011), pp. 506-517.

_. "Letras, notas y estrellas. 2a Parte". MHNH. Revista internacional de investigación sobre magia y astrología antiguas, 12 (2012), pp. 199-236.

Machielsen, Iohannis. Clavis Patristica Pseudoepigraphorum Medii Aevi, 4 vols. Turnhout: Brepols, 1994.

Marrou, Henri Irenée (Henri Davenson). Traité de la musique selon l'esprit de Saint Augustin. Neuchatel: La Baconnière, Cahiers du Rhône, 1942.

Mckinnon, James. Music in Early Christian Literature . Cambridge: Cambridge University Press, 1987; publicación en línia, 2012.

Migne, J. P. Sancti Isidori Hispalensis opera omnia. Recensente Faustino Arevalo. Patrologiae Latinae Tomus LXXXILXXXIV. París: 1862.

Moutsopoulos, Evanghélos. La musique dans l'oeuvre de Platon. París: Presses Universitaires de France, 1989.

Mynors, R. A. B. Cassiodori Senatoris Institutiones. Oxford: Clarendon Press, 1937.
Oroz Reta, José, y Manuel A. Marcos Casquero. Isidoro de Sevilla. Etimologías. Edición bilingüe, texto latino, versión española y notas. Introducción general por Manuel C. Díaz y Díaz. Madrid: Biblioteca de Autores Cristianos, 2004.

Otaola, Paloma. El De musica de san Agustín y la tradición pitagórico-platónica. Valladolid: Estudio Agustiniano, 2005.

Pagan. Samuel. El rey David: una biografía no autorizada. Viladecavalls, Barcelona: Clie, 2013.

Ramos Torres, Manuel. Casiodoro. Institutiones saecularium litterarum. Las siete artes liberales. Valdemorillo: La hoja del monte, 2009

Rodríguez Adrados, Francisco, y Juan Rodríguez Somolinos. Diccionario Griego-Español (versión en línea). Madrid: CSIC, CCHS, ILC <http://dge.cchs.csic.es/. 32>.

Sallmann, Nicolas. Censorini De die natali liber ad Q. Caerellium. Accedit anonymi cuiusdam epitoma disciplinarum (Fragmentum Censorini). Leipzig: Bibliotheca Scriptorum Graecorum et Romanorum Teubneriana, 1983.

Thesaurus Linguae Latinae, Munich: Bayerische Akademie, $<$ https://www.degruyter.com/view/db/tll>.

Vallance, J. T. The lost theory of Asclepiades of Bithynia. Oxford: Clarendon Press, 1990.

. "The medical system of Asclepiades of Bithynia". En Rise and Decline on the Roman World editado por W. Haase y H. Temporini. Berlin: de Gruyter, 1993, pp. 693727.

West, M. L. Ancient Greek Music. Oxford: Clarendon Press, 1992.

Willis, Iacobus. Martianus Capella. Leipzig: Bibliotheca Scriptorum Graecorum et Romanorum. Teubneriana: 1983.

Recibido: 08.04.2019

Aceptado: 06.09.2019 